\title{
The Design of the Sovereign Debt Restructuring Mechanism - Further Considerations
}




\section{INTERNATIONAL MONETARY FUND}

\section{The Design of the Sovereign Debt Restructuring Mechanism-Further Considerations}

Prepared by the Legal and Policy Development and Review Departments

(In consultation with the International Capital Markets and Research Departments)

Approved by François Gianviti and Timothy Geithner

November 27, 2002

Contents

Introduction $\underline{3}$

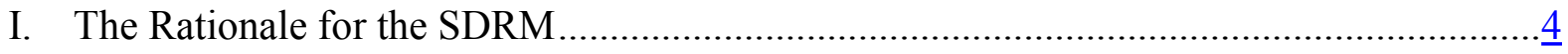

II. Principles Guiding The Design of the Mechanism .....................................................

III. Executive Summary of Key Recommended Design Features ....................................... $\underline{8}$

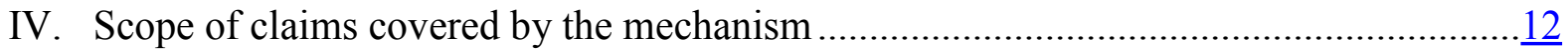

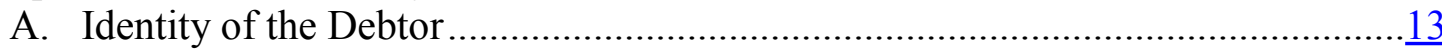

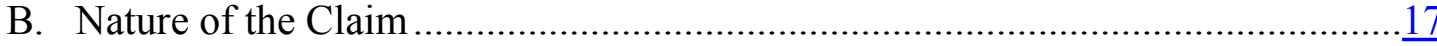

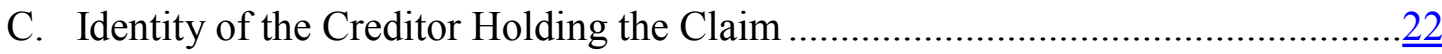

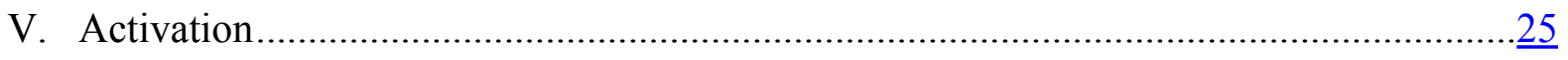

VI. Consequences of Activation ........................................................................... 27

A. Provision of Information, Registration and Verification ................................ $\frac{27}{33}$

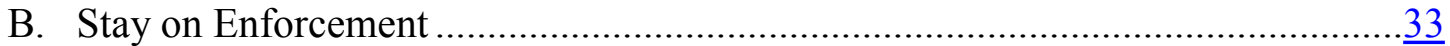

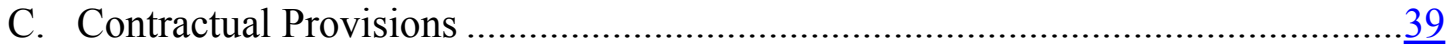

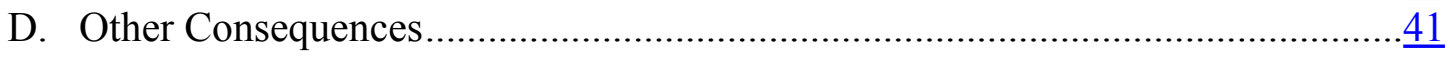

VII. Creditor Participation: Organization, Voting and Decisions...................................... $\underline{42}$

A. Creditor Organization: The Role of Creditors' Committees............................... $\frac{42}{44}$

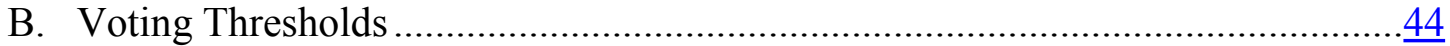

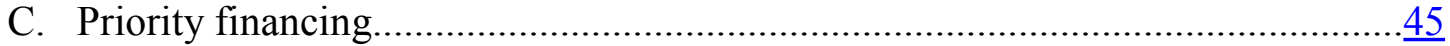

D. Restructuring Agreement ....................................................................

VIII. Sanctions ….................................................................................................. 54 


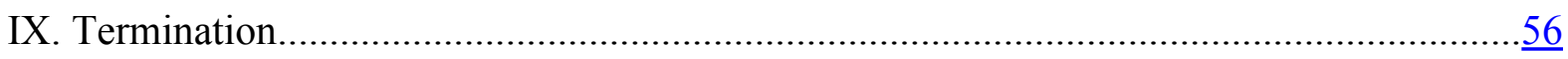

X. The Sovereign Debt Dispute Resolution Forum (SDDRF) ………………………........

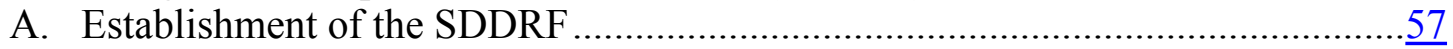

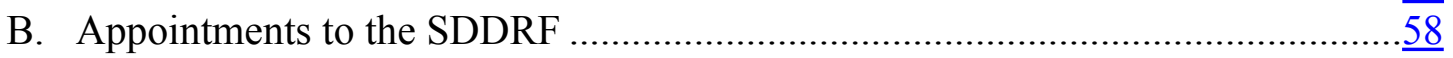

C. Organization of the SDDRF ..........................................................................61

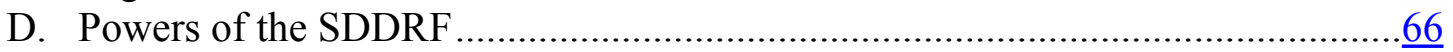

E. Accountability and Transparency of the SDDRF ................................................

XI. The Amendment and its Consistency with Domestic Legal Systems ...............................

A. Amending the Fund's Articles ....................................................................

B. Consistency with Domestic Legal Systems …………………………………...

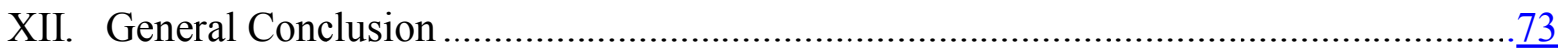

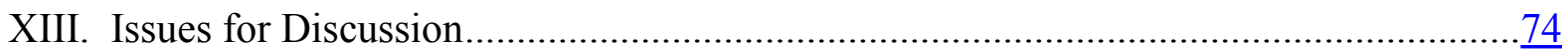




\section{INTRODUCTION}

1. This paper is a first step in responding to the request by the IMFC that the Fund develop, for consideration at the IMFC's meeting in April 2003, a concrete proposal for a statutory sovereign debt restructuring mechanism to be considered by the membership. Following the Board's consideration of the issues raised in this paper (which will be preceded by an informal seminar), a revised paper will be prepared, which-depending on the outcome of the discussions - will include an initial draft of the text of the amendment to the Fund's Articles. A report of the Executive Board to the IMFC would then be prepared in time for the IMFC's April 2003 meetings. Depending on the progress made by the Board on these issues, this report could include a revised draft of the text of an amendment and an associated commentary. Consistent with the approach that has been taken with earlier amendments of the Fund's Articles, this commentary would eventually take the form of a report by the Executive Board to the Board of Governors.

2. This paper focuses on a number of questions relating to the design of the SDRM. It does not discuss the broader range of economic, financial and policy issues that arise in the context of a restructuring of unsustainable sovereign debt, many of which will not be resolved through the establishment of the SDRM. These issues will be analyzed in a companion paper that will be circulated shortly after the Board discussion of this paper.

3. This paper has benefited considerably from consultation with market participants and members of the judicial and legal professions. Consistent with the Board's request, the staff is intensifying its outreach efforts in order to build a consensus on the need for - and design of - an SDRM. To that end, the Fund will be hosting a conference on the SDRM in midJanuary 2003. Conference participants will include representatives of emerging market countries, key policy makers, market participants, academics and members of the legal and judicial professions. The feedback obtained from this conference will be taken into consideration in the preparation of the revised version of this paper and the initial draft of the text of the amendment to the Fund's Articles.

4. This paper is organized as follows. Distilling the analysis that has been developed during earlier discussions, Section I briefly discusses the rationale for the SDRM. Section II identifies a number of general principles that may provide useful guidance when resolving a number of the difficult legal and financial issues that arise when designing the mechanism. Section III contains an executive summary of the key design features of the SDRM. The scope of debt that could be potentially covered under the SDRM is discussed in Section IV. The conditions for activation are analyzed in Section V, while Section VI discusses the key consequences that will flow from this activation. Section VII discusses how creditors would participate in the restructuring process and, in that context, analyses issues relating to organization, voting and decisions, including the decision to accept a restructuring agreement. Section VIII discusses the various types of sanctions that could be considered to create disincentives for the abuse of the mechanism. The termination of the SDRM is discussed in Section IX. Issues relating to the establishment and powers of the Sovereign 
Debt Dispute Resolution Forum are considered in Section X. Section XI addresses questions relating to the amendment process itself and the consistency of such an amendment with the domestic laws of members. Section XII sets forth a general conclusion. Issues for discussion are identified in Section XIII.

5. The highlighted text in each section of the paper attempts to summarize the staff's preliminary recommendation as to how a specific feature of the SDRM could be designed.

\section{THE RATIONALE FOR THE SDRM}

6. On occasion, countries may experience severe financial difficulties as a result of major portfolio imbalances in one or more sectors of the economy. Clearly, in cases in which balance sheet difficulties extend beyond the sovereign, a resolution of financial crises and a return to sustainable growth will require that adjustments to a sovereign's debt burden be complemented by measures to restructure the banking system and/or to restore the solvency of the corporate sector. Moreover, to the extent that crises trigger capital flight, it may be necessary to make temporary resort to some combination of exchange controls and administrative limitations on the liquidity of bank deposits. Accordingly, by providing a framework that addresses the restructuring of sovereign debt, it is recognized that the SDRM would constitute only one element of a broader crisis resolution strategy, albeit a central one.

7. In extreme cases, a sovereign's debt burden may be unsustainable. More specifically, members could confront situations where there is no feasible set of sustainable macroeconomic polices that would allow the member to resolve the current crisis and regain medium-term viability without a significant reduction in the net present value of the sovereign's debt. Judgments about sustainability, which involve an assessment a country's capacity to keep its total debt under control without unrealistically large corrections in the balance between income and expenditure, underpin the Fund's decisions in program contexts, helping to determine when Fund financing is appropriate. Debt sustainability depends on the confluence of several factors - including macroeconomic developments, political and social constraints on adjustment, and the availability and cost of private and official financing.

8. Because a debt restructuring imposes great costs on sovereign debtors, countries have gone to extraordinary lengths to avoid a restructuring before finally recognizing the need for a debt adjustment. Yet experience demonstrates that delays only magnify these $\operatorname{costs}{ }^{1}$, both in terms of losses in reserves and, more generally, in a decline in economic output.

\footnotetext{
${ }^{1}$ As highlighted in a review of recent country experience, a default or a restructuring in the shadow of default may involve declining real incomes, sharply curtailed private investment, financial sector difficulties, and drainage of external reserves in the attempt to stem pressures from capital outflows. The impact on the domestic economy and the links between sovereign debt restructurings, currency crises and banking crises in recent cases were analyzed in
}

(continued) 
9. The interests of most creditors are also damaged by these delays. The value of their claims would be better preserved if the debtor acted at an early stage, thereby helping to preserve the economic value of financial and nonfinancial corporations and the capacity of the economy to generate tax revenue. Asset values would also be better preserved if uncertainty over recovery values were to be reduced. Such uncertainty may exacerbate risks of a rush to sell, which would depress secondary market prices and impose large mark-tomarket losses. Uncertainty also makes it very difficult to rollover maturing claims, thereby exacerbating the uncertainty for sovereign debtors.

10. Delays in the initiation of the restructuring process are attributable, in part, to uncertainties associated with how this process will unfold. Perhaps most importantly, members with unsustainable debt burdens and a diffuse group of creditors may face substantial difficulties in reaching a rapid agreement with their creditors on a restructuring that would restore sustainability. Collective action difficulties, which result from incentives for individual creditors to hold out in the hope of obtaining more favorable terms, complicate the task of achieving broad participation in restructurings that may serve the interests of both the debtor and creditors as a group. ${ }^{2}$ By the same token, difficulties in achieving adequate inter-creditor equity may also inhibit creditors from accepting proposed restructurings, thereby prolonging the process. In some respects, collective action difficulties may be most acute prior to a default, where individual investors may decide not to participate in a restructuring in the hope of continuing to receive payments in line with the original terms of their claims.

Sovereign Debt Restructurings and the Domestic Economy-Experience in Four Recent Cases, SM/02/67 (2/21/02).

${ }^{2}$ It is worth noting that efforts to resolve collective action difficulties also provide the motivation for contractual approaches to improving sovereign debt restructuring mechanisms.

${ }^{3}$ Recent developments in capital markets have amplified these difficulties. The last 15 years have witnessed a shift away from syndicated commercial bank lending toward a variety of tradable financial instruments issued in a number of legal jurisdictions that are held by a diffuse and broad base of creditors. In many respects, this is a positive development, as it has broadened the investor base for financing emerging market sovereigns, and has facilitated the diversification and management of risk. However, the diversity of claims and interests could generate significant coordination problems across claims and claimants in cases where a sovereign decides to seek the restructuring of its debt. The narrow range of debt instruments containing contractual provisions that could facilitate a restructuring may provide only limited help in achieving rapid agreement in cases in which the member has substantial indebtedness that does not include such provisions. Moreover, the effectiveness of contractual provisions in individual instruments would be limited to the extent that potential holdout creditors are able to acquire controlling interests in individual bond issues. 
11. While much of the existing uncertainty is attributable to collective action problems, there are other factors that hamper the restructuring process. For example, inter-creditor equity problems are exacerbated by a perception that insufficient information is made available regarding the debtor's relative treatment of different creditor groups. In addition, creditors have also expressed concern that sovereign debtors are reluctant to engage in a collaborative dialogue to develop restructuring proposals. Of course, delays in reaching an agreement on a restructuring may also result from delays in the formulation and implementation of a comprehensive macroeconomic and structural reform program.

12. Against this background, there is now an increasing recognition in both the official sector and private markets that the current process for restructuring the debt of a sovereign needs to be improved. The current process imposes undue costs on both the debtor country and its creditors, because it is prolonged and unpredictable. It may also risk contributing to contagion, with associated costs and risks for the stability of the international financial system.

13. Accordingly, the objective of the sovereign debt restructuring mechanism is to provide a framework that strengthens incentives for a sovereign and its creditors to reach a rapid and collaborative agreement on a restructuring of unsustainable debt in a manner that preserves the economic value of assets and facilitates a return to medium-term viability. For such a mechanism to achieve this objective, it must not only address collective action problems amongst creditors but also catalyze an early and effective dialogue between the debtor and its creditors. To the extent that a mechanism can achieve this objective in a manner that creates greater predictability in the restructuring process, it will also improve the functioning of international capital markets.

\section{Principles Guiding The Design of the Mechanism}

14. The design of a mechanism that would achieve the above objectives inevitably raises a wide range of complex issues of a legal and financial nature. With a view to ensuring that these issues are resolved in a manner that achieves the above-stated objective, it would be helpful to develop a set of general principles that could help guide the design of the mechanism. To this end, the following principles are proposed for consideration.

- The mechanism should only be used to restructure debt that is judged to be unsustainable. The purpose of the SDRM is to reduce the costs of restructuring debt that creditors and sovereign debtors recognize will need to be restructured anyway. It should neither increase the likelihood of restructuring nor encourage defaults.

- In circumstances where a member's debt is unsustainable, the mechanism should be designed to catalyze a rapid restructuring. One of the reasons why the cost of restructuring is so high is that it is subject to undue delays, both in terms of when the restructuring process is initiated and, once initiated, its duration. For this 
reason, the mechanism should create incentives for an early and collaborative engagement between the debtor and its creditors and should establish a procedure that enables the restructuring process to be completed within a reasonable time frame.

- Any interference with contractual relations should be limited to those measures that are needed to resolve the most important collective action problems. The principal feature of the mechanism is that it would allow a sovereign and a qualified majority of creditors to reach an agreement that would then be made binding on all creditors that are subject to the restructuring, paying due regard to seniority among claims. The merits of including any other measure that would interfere with contractual relations must be assessed in terms of (i) whether it resolves a critical collective action problem and (ii) whether it does so in a manner that minimizes interference with contractual rights and obligations.

- The framework should be designed in a manner that promotes greater transparency in the restructuring process. Accordingly, the mechanism should establish procedures that enable creditors to have adequate access to information regarding the debtor's general situation, including its overall debt (and its treatment of creditors that may not be subject to the mechanism), economic prospects and policies, and the proposed financing plan.

- The mechanism should encourage early and active creditor participation during the restructuring process. In addition to providing for a creditor vote on the terms of a restructuring, the framework should enable creditors to play an active role at earlier stages in the process, including through the formation of creditors' committees.

- The mechanism should not interfere with the sovereignty of debtors. The mechanism could not be activated without the sovereign's request. Accordingly, the sovereign would only seek to activate the mechanism when it had formed a judgment that the features of the SDRM would enhance its capacity to restructure its debt rapidly and in a manner that limits economic dislocation.

- The framework should establish incentives for a negotiation-not a detailed blue print for a restructuring. The process of restructuring sovereign debt is relatively complex, requiring the resolution of a number of difficult substantive and procedural questions. To the extent possible, these issues should be resolved through the give-and-take of negotiations and, therefore, the mechanism should not be designed in a manner that presumes a particular outcome. For example, while the SDRM will identify the types of debt that could potentially be subject to a restructuring, whether all or only some of that debt is restructured will depend on the outcome of negotiations. 
- The framework needs to be sufficiently flexible — and simple — to accommodate the operation and evolution of capital markets. The provisions of the SDRM must be sufficiently clear for the process to be predictable. At the same time, however, it should avoid relying on overly detailed and narrow rules and definitions that will only invite future circumvention through financial engineering.

- Since the framework is intended to fill a gap within the existing financial architecture, it should not displace existing statutory frameworks. For example, the SDRM should not be used to restructure the claims of public entities that are already subject to domestic insolvency systems.

- The integrity of the decision making process under the mechanism should be safeguarded by an efficient and impartial dispute resolution process. Since the mechanism will aggregate diverse claims for voting and restructuring purposes, disputes are likely to arise as to the validity and value of these claims. Resolving these disputes in a fair, impartial and expeditious manner is critical to the success of the restructuring exercise.

- Finally, the formal role of the Fund under the SDRM should be limited. Although the SDRM would be established through an amendment of the Fund's Articles of Agreement, the SDRM should not give the existing organs of the Fund any significant new legal powers. To the extent that the Fund can play a useful role in creating incentives for an appropriate use of the mechanism, these incentives should be established through the use of its existing financial and surveillance powers. In the final analysis, however, the framework should be designed to catalyze early and effective dialogue between the debtor and creditors - it should not increase the role of the Fund in this dialogue.

\section{EXeCUTIVE SUMmary OF Key ReCommended DeSIGN FeATURES}

\section{Scope of Claims to Be Covered}

15. While the mechanism would identify the scope of claims that could potentially be subject to a restructuring ("eligible claims"), whether all or some these claims would be restructured in a particular case would depend on the negotiations between the debtor and its creditors. As a general rule, eligible claims would include all rights to receive payments relating to the commercial activities of the sovereign. The central government would have the option to include its own debt and, subject to the consent of the debtor in question, claims on: (i) the central bank and (ii) public entities or subnational governments that are not subject to a domestic insolvency framework. 
16. Specific exclusions from "eligible claims" would include:

- Claims that are governed by domestic law and subject to the exclusive jurisdiction of the domestic courts. Although such claims would be restructured outside the SDRM, the transparency requirements of the SDRM would ensure that holders of external claims were aware of the terms being offered to the holders of domestic claims when they vote on a proposed restructuring agreement under the SDRM.

- Claims that benefit from privileges, such as secured claims, which could not be restructured absent the individual consent of the creditor in question. However, to the extent that the value of the claim exceeds the value of the privilege, the "undersecured" portion would be subject to restructuring under the SDRM.

- Claims held by international organizations, reflecting the unique role these institutions play in the existing international financial system.

17. A threshold issue to be resolved is whether the claims held by official bilateral creditors would be restructured outside the SDRM or, alternatively, would be restructured under the SDRM as a separate class.

\section{Activation}

18. Consistent with the principle of sovereignty, the mechanism could only be activated at the initiative of the member. When activating the mechanism, the member would represent that it had formed the judgment that its debt was unsustainable. A critical question to be resolved is whether it would be necessary to provide for an independent confirmation of the accuracy of the member's representation of unsustainability as a condition for activation and, if so, what entity would perform this function.

\section{Consequences of Activation}

19. Upon activation, a procedure would unfold that would require the debtor to provide all information regarding its indebtedness (including debt that will not be restructured under the SDRM) to its creditors. Moreover, an expeditious registration and verification process would take place that would enable creditors to be in a position to vote on an aggregated basis. This would need to accommodate secondary market trading. The Sovereign Debt Dispute Resolution Forum (the SDDRF) would resolve disputes arising during the verification process.

20. Activation would not automatically trigger any suspension of creditor rights. There would be no generalized stay on enforcement and no suspension of contractual provisions, (including provisions relating to the accrual of interest). However, and as a means of ensuring inter-creditor equity, if creditors eventually approved a restructuring agreement under the SDRM, amounts recovered by a creditor through litigation would be deducted from its residual claim under that agreement in a manner that neutralizes any benefits of such litigation vis-a-vis other creditors. A question arises as to whether it would also be helpful to 
enable the debtor-but only upon approval of creditors subject to the SDRM-to request the SDDRF to enjoin specific enforcement actions in circumstances where such enforcement could undermine the restructuring process.

\section{Creditor Participation: Organization, Voting and Decisions}

21. Creditors' Committees As a means of encouraging active and early creditor participation in the restructuring process, a representative creditors' committee would be given a role under the SDRM to address both debtor-creditor and intercreditor issues. Disputes as to whether a committee was sufficiently representative would be resolved by the $S D D R F$. Consistent with best practices in this area, the debtor would bear the reasonable costs associated with the operation of these committees. However, the SDDRF would have the authority to review these fees and reduce them where they appear to be excessive.

22. Voting Thresholds Subject to the classification rules set forth below, creditor approval of proposals made by the debtor regarding either priority financing or the terms of restructuring would be made by 75 percent of the outstanding principal of those registered and verified claims that are subject to the restructuring. By their own motion, creditors could also vote to terminate the mechanism after the verification process. A question arises as to appropriate threshold for this vote.

23. Priority financing As a means of inducing new financing, it would be appropriate for the SDRM to provide that a specified amount of financing (or a specified financing transaction) would be excluded from the restructuring if such exclusion is supported by 75 percent of outstanding principal of registered claims.

24. Restructuring Agreement When a sovereign debtor proposes a restructuring agreement, it would also be required to provide information as to how it intends to treat claims that are not to be restructured under the SDRM. This will enable holders of registered claims to make a decision regarding the sovereign's proposal with the full knowledge of how other claims are to be treated. All holders of registered claims would be asked to vote on the proposed restructuring agreement. Subject to the classification rules discussed below, the agreement would become binding on all registered creditors once the vote has been certified by the SDDRF. It would also become binding on all creditors that were notified that their claims were to be restructured under the SDRM but who failed to register.

25. If the claims of official bilateral creditors are subject to restructuring under the mechanism, they would be placed in a separate class. Although this would enable each class to receive different terms, approval by the requisite majority in both classes would be necessary for the overall restructuring agreement to become effective. As a means of facilitating a restructuring agreement amongst creditors with different preferences, the sovereign would also have the option-but not the obligation-of creating different classes among private creditors. However, this ability would be limited by a requirement that such classes not be created in a manner that results in unjustified discrimination of creditor groups, taking into consideration their varying economic interests. A debtor would not be 
required to place creditors in different classes solely because of the varying maturities or interest rates of their original instruments. For purposes of voting under the SDRM, all claims would be deemed due and payable and could, accordingly, be aggregated for voting purposes.

\section{Sanctions}

26. It is recommended that the provision of false information by the sovereign during the restructuring process constitute a breach of the member's obligations under the Articles of Agreement. With respect to sanctions for noncooperation or inappropriate use of the mechanism, it is recommended that the Fund would rely on its existing financial policies, including its lending into arrears policy.

\section{Termination}

27. The SDRM procedure would automatically terminate upon the certification of the restructuring agreement by the SDDRF. In addition, and consistent with the principle of sovereignty, the sovereign debtor could terminate the operation of the mechanism at any time, although disincentives would need to be in place to ensure that this right is not exercised in a manner that results in an abuse of the mechanism. The SDDRF would have the power to terminate the operation of the mechanism prior to a restructuring agreement on the basis of a determination that there was no reasonable prospect for a restructuring agreement. Following the verification process and upon their own motion, creditors could vote to terminate the procedure where they are of the view that activation is not justified.

\section{Sovereign Debt Dispute Resolution Forum}

28. The Sovereign Debt Dispute Resolution Forum (SDDRF) would be established in a manner that ensures independence, competence, diversity and impartiality. The proposed procedure for the establishment and operation of the SDDRF may be summarized as follows:

- First, upon the advice of relevant professional associations and existing international organizations with experience in this area, the Managing Director would designate a selection panel of 7-11 highly qualified judges or private practitioners.

- Second, the selection panel would be charged with identifying 12-16 candidates that would constitute the pool from which judges would be impaneled when a crisis arises. Although the amendment would specify the qualification criteria (e.g., judicial experience in debt restructuring matters), the nomination process would be an open one. Once selected, this pool would be approved by the Board of Governors by an "up or down" vote. Except for the President of the SDDRF, all of members of the pool would continue to work in their own countries and in their other capacities until impaneled. 
- Third, when the SDRM is activated, four judges from the pool would be impaneled by the President of the SDDRF. One of these judges would be responsible for making initial determinations. The remaining three judges would constitute an appeals panel.

29. The powers of the SDDRF would be limited. It would have no authority to challenge decisions of the Executive Board or make determinations on issues relating to the sustainability of a member's debt. Its primary functions may be summarized as follows:

- Administrative Functions - this would include notification to creditors, registration of claims and administration of the voting process.

- Dispute Resolution - the SDDRF would be charged with resolving disputes that will arise during the restructuring process and would have exclusive jurisdiction over such disputes during this period. These disputes will arise during the claims verification procedure (challenges will be made with respect to the validity and value of claims) and the voting process (where disputes may arise as to whether certain creditors should be disqualified because they are controlled by the sovereign). Disputes may also arise in the context of the formation and operation of creditors' committees. In performing this function, the SDDRF will be reactive: it will not initiate investigations regarding potential abuses, but will merely adjudicate allegations of abuse brought by a party. While it could request the parties to provide evidence, it would have no subpoena power.

- Injunctive Relief-Depending on the design of the SDRM, the SDDRF would be empowered to issue an order that would require a court outside the territory of the sovereign to stay a specific enforcement action if such an order was requested by the debtor and approved by creditors subject to the SDRM. If this approach were to be given further consideration, a question would arise as to how creditor approval would be obtained.

\section{Legal Basis of the SDRM and its Consistency with Domestic Laws}

30. The SDRM and the SDDRF could be established through an amendment of the Fund's Articles, which requires acceptance by three-fifths of the members, having 85 percent of the voting power. Since the amendment will involve the establishment of new treaty obligations, most countries will need legislative authorization for acceptance, Moreover, some members will also need to enact domestic legislation to give the amendment full force and effect. It is up to each member to determine the extent to which the adoption of the $S D R M$ would require changes in its domestic laws.

\section{SCOPE OF CLAIMS COVERED BY THE MECHANISM}

31. There is general agreement that, in cases in which a sovereign's debt burden is unsustainable, the scope of claims that may need to be included in the restructuring will 
likely be broad. On the one hand, this will be needed to engineer a sufficient adjustment to the debt and debt service profile to create reasonable prospects for a return to viability. On the other hand, a broad coverage of debt, taking due account of the differing economic interests of the various parties, is likely to be necessary in order to achieve sufficient intercreditor equity to garner broad support for a restructuring.

32. Notwithstanding the likely need for a broad restructuring, a debtor may decide to exclude certain types of claims from a restructuring, particularly where such exclusion is needed to limit the extent of economic and financial dislocation. By way of example, a debtor may decide to exclude trade credit and certain types of domestic money market instruments (such as Treasury bills) so as to preserve its continued ability to mobilize these types of financing. Clearly, creditors holding instruments that are to be covered by a restructuring will take a keen interest in the design of the proposed financing package, and will want to ensure that exclusions from a restructuring serve to help preserve a debtor's capacity to generate resources for debt service, rather than increasing the burden on those included in the restructuring.

33. As will be discussed below, it is envisaged that, while some claims that are to be restructured would be covered by the SDRM, others would be restructured in parallel using existing techniques for resolving collective action difficulties (e.g., claims governed by domestic law that are subject to the exclusive jurisdiction of the local courts), in a fashion that could be coordinated with, and complementary to, restructurings under the SDRM. However, even if claims were not be restructured under the SDRM, the transparency requirements that would be established under the mechanism would greatly enhance the ease of coordinating these parallel restructuring processes.

34. It is recommended that the provisions of the SDRM would identify the range of claims that could be potentially restructured under the mechanism ("eligible claims"), leaving it to the debtor to determine which subset of eligible claims would need to be restructured in a particular case. While it would be for the debtor to propose the subset of eligible claims that would be covered in a restructuring, this is likely to require consultation between a debtor and its creditors so as to ensure that the proposed framework could attract broad creditor support.

35. The remainder of this section discusses in detail how the provisions of the mechanism could define eligible claims, taking into consideration three different components of this definition: (i) the identity of the debtor; (ii) the nature of the claim against the debtor; and (iii) the identity of the investor holding the claim.

\section{A. Identity of the Debtor}

36. Although it is generally agreed that the mechanism will be limited to the restructuring of sovereign claims, the definition of what will constitute "sovereign" claims for purposes of the mechanism raises a number of questions. The most important of them are discussed below. 


\section{Central Government}

37. Only the central government of a member would be able to activate the SDRM. Once activated, all eligible claims (to be defined below) on the central government could be brought into the SDRM restructuring process. For this purpose, the central government would include all administrative divisions and agencies that form part of the central government's budgetary process.

\section{Central Bank}

38. Debt is often considered "sovereign" if it is issued either by the central government or the central bank/monetary authorities of a country. ${ }^{4}$ Yet because central banks are separate legal entities, claims on the government do not as such constitute claims on the central bank (and vice versa) absent the existence of a guarantee. Accordingly, the decision of the central government to restructure its own debt does not automatically mean that the central bank's indebtedness will also be restructured. Indeed, there have been cases in the past where a government has defaulted on its own indebtedness while the central bank has continued to service its claims. Of course, in circumstances where the government wishes to restructure its own debt, the government's creditors may very well insist that the central bank's debt also be subject to the restructuring process. However, in countries where a central bank is independent, this would require the central bank's consent.

39. In light of the above, the following approach could be taken: when the government of a member wishes to activate the SDRM to restructure its own indebtedness, it would also have the option-but would not be required-to include the debt of the central bank. ${ }^{5}$ Whether a government would actually decide to bring central bank debt within the SDRM in a particular case would depend on the circumstances, including the attitude of its creditors on this question.

\section{Public Entities}

40. A separate question arises as to the potential coverage of public entities that are established as separate legal entities rather than as administrative departments of the central government and which do not form part of the central government's budgetary process. Such entities may be established by statute or may be corporations that are owned or otherwise controlled by the government. To the extent that they are engaged in commercial activities (e.g., state-owned oil companies or airlines), they may borrow extensively on the capital

\footnotetext{
${ }^{4} \mathrm{~A}$ number of central banks issue international sovereign bonds, including those of Hungary and the Philippines.

${ }^{5}$ In the event that the debtor wished to exercise this option, it would need to obtain the consent of the central bank if the domestic law of the member so required.
} 
markets. Moreover, the government may establish special purpose vehicles for the specific purpose of raising financing.

41. Should the government have the option of using the mechanism to restructure the debt of these entities? One approach would be to give the government this option only where the entity in question is not subject to the domestic insolvency laws of the member. ${ }^{6}$ Such an approach would be consistent with the general principle that, to the extent possible, the SDRM should avoid displacing existing statutory frameworks that are otherwise available to restructure claims. Moreover, ensuring that the restructuring of claims of state-owned enterprises is subject to the exclusive ambit of a member's general domestic insolvency law would be consistent with emerging best practices in this area. ${ }^{7}$ There is a general recognition that such an approach has the advantage of both subjecting the enterprise to the discipline of the market place and sending a clear signal that government financial support will be limited. Indeed, extending the general insolvency law to government-owned enterprises has the advantage that the rehabilitation provisions of an insolvency law can effectively ensure that creditors contribute to the resolution of the financial problems of these companies, thereby limiting the public cost of rehabilitation.

42. If public entities that are subject to a domestic insolvency framework were to be excluded, it would mean that the potential application of the mechanism in each case would, in turn, depend on the scope of the insolvency laws of each member. However, to the extent that the official community actively develops and promotes best practices and standards with respect to the application of domestic insolvency law to state enterprises, the scope and quality of the laws of member countries should converge. Indeed, defining the scope of the SDRM in terms of coverage of domestic insolvency laws could serve to catalyze further uniformity and improvements in this area.

43. There may be circumstances, however, where, as an economic and financial matter, the restructuring of the government's own debt cannot be separated from the restructuring of the claims on state-owned enterprises. In cases where the enterprise has been borrowing on behalf or for the benefit of the government (i.e., where it has been on-lending the proceeds of

\footnotetext{
${ }^{6}$ This criterion would be controlling. Accordingly, in circumstances where the public entity is subject to the domestic insolvency law, it would be excluded even if it formed part of the budgetary process.

${ }^{7}$ Perhaps most significantly, the United Nations Commission on International Trade Law (UNCITRAL) has almost completed a legislative guide that would provide guidance as to the design of a domestic insolvency law that would be applicable to both developed and developing countries. The World Bank and the Fund have also done work in this area. The Bank will soon be finalizing its "Principles and Guidelines for Effective Insolvency Systems". In 1999, the Fund's Legal Department published "Orderly and Effective Insolvency Procedures: Key Issues."
} 
the borrowing to the central government), creditors of the sovereign may insist that, as a matter of intercreditor equity, such claims on the enterprise be included in the restructuring process. In these cases, the domestic insolvency law may provide a framework that will enable these claims to be restructured in parallel with the claims on the sovereign. This may be particularly relevant where the claims of the enterprise on the sovereign (arising from the onlending) also need to be restructured.

44. Would the exclusion of public entities, as suggested above, give rise to circumvention? To the extent that the exclusion of such instrumentalities creates incentives for the sovereign to borrow through "shell" special purpose vehicles, it is unlikely that the creditor would lend without a sovereign guarantee. In such circumstances, a sovereign wishing to restructure the claims on these companies (other creditors of the sovereign may also insist on the restructuring of these claims) could simply cause the shell company to default, which would trigger the guarantee.

\section{Subnational Governments}

45. Although some subnational governments (provinces, states and municipalities) have established access to capital markets, most countries have not established statutory frameworks that provide for the restructuring of these claims. Should the national government have the ability to restructure the obligations of subnational governments under the SDRM? In cases in which subnational governments have unsupportable debt burdens, the creditors of the sovereign are likely to require the restructuring of subnational governments' debts as a condition for restructuring the claims of the sovereign. Accordingly, providing the option for the central government to include the debts of subnational governments under the SDRM would help to ensure that the combined fiscal position of the central and subnational governments are sustainable, and that uncovered financing needs of subnational governments do not undermine fiscal stability. Consistent with the criterion used for public enterprises, however, subnational government could only be included where the member has not already established a legal framework that restructures such indebtedness. ${ }^{8}$

46. It should be recognized that, even if the SDRM were limited to subnational governments or public entities that are not subject to domestic insolvency laws, the inclusion of the SDRM process would embrace parallel restructurings. Specifically, unless the government actually assumes the debt of these entities upon activation (which would normally require the consent of the creditors), there would be more than one debtor. Each debtor (the central government, the central bank, a public entity, or a subnational government) would ask its creditors to take decisions described in the subsequent sections of this paper. Moreover, creditors would only take decisions with respect to the entity that it has

\footnotetext{
${ }^{8}$ An example of such a framework is Chapter 9 of the U.S. Bankruptcy Code, which provides a framework for the restructuring of claims of municipalities and local governments.
} 
a claim on. As will be discussed in Section VII, the framework will need to ensure that these restructuring exercises are adequately coordinated.

47. In light of the above considerations, it is recommended that the sovereign could only bring claims on public entities and subnational governments into the SDRM if these entities were not subject to any domestic insolvency system.

\section{B. Nature of the Claim}

48. What type of claims on the sovereign could potentially be subject to the mechanism? Defining claims on the sovereign in terms of claims arising from the extension of credit to, or the guarantee of credit by, a sovereign, provides a useful starting point. ${ }^{9}$ In practice, however, such definitions could readily be circumvented through the use of a wide range of contractual techniques ${ }^{10}$ that could, over time, limit the utility of the mechanism. Accordingly, a somewhat broader definition is warranted.

\section{Proposed definition of eligible claims}

49. Subject to the exceptions discussed below, it is recommended that an eligible claim would be defined as a right to receive a payment under a contract (whether in money or in goods) relating to commercial activities of the "sovereign". An activity would be considered "commercial" if it could be conducted by a private party, i.e., it would not be limited to activities where the sovereign is engaging in the activity for a commercial purpose, i.e., as a merchant.

50. Claims covered by this definition would include, but not be limited to, the following contractual rights:

- Repayment of money lent or credit advanced;

- Receipt of deferred purchase price of goods or services;

- Payments under bonds, notes or similar instruments;

- Amounts payable under interest rate and currency swaps, and other financial derivatives;

\footnotetext{
${ }^{9}$ This is the approach adopted for the purposes of debt limits in Fund arrangements. For that purpose, the concept of the extension of credit has been broadened to encompass financial and operating leases.

${ }^{10}$ Such techniques could include the use of insurance contracts as well as financial derivatives under which payment obligations could arise from specified events.
} 
- The right of an issuing bank to be reimbursed for payments made under a letter of credit, bankers acceptance or bond;

- Payments due under leases;

- Guarantees or insurance contracts (direct or indirect) of the indebtedness of another party (subject to the exclusion below).

51. The definition of eligible claims would include court judgments requiring payment for liability on eligible claims.

52. The definition of eligible claims necessarily excludes noncontractual claims and claims arising from non-commercial activities. Such excluded claims would include, but would not be limited to:

- Wages, salaries, and pensions;

- Subscriptions to international organizations;

- Tort claims;

- War crime and human rights violation claims;

- Claims arising from expropriation.

53. Although the above definition would mean that a broad class of claims could be made subject to the SDRM, it does not mean that all of these claims would be treated in the same manner. Moreover, there would also need to be a specific exclusion for certain types of claims. In that context, the treatment of some particularly important claims is discussed below.

\section{Guarantees and Contingent Obligations}

54. Government guarantees can take many forms and may be extended for different purposes. Governments may guarantee specific obligations of enterprises, whether stateowned or otherwise, for the purpose of reducing the cost of credit for these enterprises. In the context of financial crises, governments have guaranteed the obligations of the entire banking system as a means of forestalling a run on deposits and interbank credit lines. In terms of the type of risks that are covered, guarantees can address credit risk (i.e., the risk of default arising from the financial weakness of the obligor) or transfer risk (i.e., default arising from the imposition of exchange controls).

55. How should guarantees be covered under the SDRM? One approach would be to enable the member to restructure a guarantee under the SDRM only after the guarantee has been called by the creditor; i.e., after there has been a default on the underlying obligation that is being guaranteed. Under this approach, guarantees, as contingent obligations of the sovereign, would be effectively excluded from the SDRM since, once they are called, they would be a direct — rather than a contingent_claim against the member. The problem with 
this approach is that it may prevent the sovereign from addressing important vulnerabilities that may arise in the future.

56. An alternative approach would be for the sovereign to have the option to include uncalled guarantees in a restructuring; i.e., they could be restructured even though the underlying claim that is guaranteed continues to be serviced. Such an approach presents its own difficulties. First, as a practical matter, it will be very difficult to restructure a guarantee without affecting the underlying claim. Indeed, a decision by the government to bring a guarantee within the scope of a restructuring under the SDRM would probably become a standard event of default under the contract that establishes the underlying claim. A second problem is the complexities of implementation. It is not clear how these contingent claims would be valued for voting and distribution purposes. In any event, it is likely that they would need to be placed in a separate voting class since their interests vary considerably from those creditors holding direct claims on the sovereign. On balance, therefore, it may be preferable to leave uncalled guarantees outside the scope of the SDRM; i.e., they could only be restructured if the underlying obligation is in default.

57. If the above approach is followed, there could be risk of circumvention. Specifically, safeguards would need to be in place to prevent a situation where the guaranteed claim goes into default prior to activation (or during the restructuring exercise) and the creditor avoids calling the guarantee until after termination of the SDRM so as to avoid having the guarantee restructured. To address this risk, a rule could be adopted that would permit the debtor to deem guarantees that could have been called following an event of default to have been called, and thereby to be covered by the restructuring. ${ }^{11}$

58. A further issue arises with respect to other types of contingent claims on sovereign debtors, such as payments falling due as a result of financial derivatives (including, for example, currency and interest rate swaps, and forward contracts). In some cases, the magnitude of these claims may be such that it would be necessary to include them in a restructuring. One approach would be to value such claims in line with their market value. In cases in which similar contracts are traded in deep secondary markets, this would be straightforward. Some degree of estimation may be required, however, in cases in which secondary markets have not developed. An alternative approach would be to delay a restructuring until the contingent claims have matured. In cases in which the claims are of very short duration, the delay may be inconsequential. In other cases, however, it could produce an unwarranted delay, thereby exacerbating uncertainty and loss of asset value.

11 By the same token, in order to help ensure that restructurings would be comprehensive, when a guarantee has been called with respect to a specific payment, the guarantee on all other payments associated with the underlying debt instrument would be deemed to have been called. 
59. In light of the above, it is recommended that guarantees only be eligible for inclusion under the SDRM if the underlying claim is in default. With respect to contingent claims other than guarantees, it is recommended that debtors should be able to include such contingent claims if they have matured or, in cases where they have not matured, it is possible to assess a market value.

\section{Privileged claims}

60. When extending credit, certain creditors will — pursuant to contractual terms or statutory provisions - have the right to collect upon pre-specified assets of the sovereign in the event of default. These contractual terms may provide for the creation of a security interest over specific collateral and, in some cases, the only recourse that a creditor has against the sovereign in the event of default is to foreclose upon this collateral; i.e., in the event that the value of the collateral is less than the value of the claim at the time of default, the creditor has no right to proceed against the sovereign for any deficiency (limited recourse financing). The contractual terms may also involve the establishment of an escrow account through which proceeds of revenues of the sovereign are deposited until the payments on the underlying credit are made. A very different type of arrangement used by banks provides for a right of acceleration and set-off; i.e., in the event of default, the bank may apply any amounts that the sovereign has deposited with the banks in satisfaction of its claim.

61. The nature of such "privileged" claims varies considerably but all of them give creditors an advantage over general unsecured creditors in the event of default. Not only do they have the assurance of being able to collect upon a specific asset, but they may also do so quickly: depending on the jurisdiction, the creditor will often have the right to collect against the debtor upon an event of default without having to first obtain a judgment from the judiciary ("self-help measures").

62. If the SDRM treats these claims in a manner that erodes the value of such privileges, it will make borrowing more difficult for those sovereigns that are unable to borrow without granting these privileges. Moreover, it would constitute a significant interference with contractual relations. As will be seen in various sections of this paper, the general approach advocated in the design of the mechanism is to give such claims preferential treatment and, most importantly, to subject the restructuring of any privileged claim to the individual consent of the creditor in question. As will be discussed, this general approach is motivated not only by the need to protect the value of these privileges, but also because alternative solutions could severely complicate the operation of the mechanism.

63. This approach is not without trade-offs: protecting the value of such privileges may limit the flexibility of a sovereign during a restructuring. Moreover, it may create incentives for greater reliance by sovereigns on the granting of such privileges - rather than the adoption of sound macroeconomic policies - as a means of attracting finance. This latter risk is mitigated by the existence of negative pledge clauses in all of the loans extended by 
multilateral development banks. By virtue of these clauses, the official sector is in a position to effectively control the amount and type of security that is granted by sovereigns. ${ }^{12}$ The Fund could also moderate the amount of secured financing in the exercise of its surveillance. Informal market contacts suggest that market participants would support this overall approach.

64. It should be noted that the exclusion of most public entities from the coverage of the mechanism would reduce the significance of security under the SDRM, since most collateralized borrowing is conducted by public entities rather than the sovereign itself. Finally, there are certain transactions, such as the forward sale of receivables, which are often constructed in a manner that they no longer give rise to claims for payment against the sovereign and, therefore, would be beyond the scope of the mechanism.

\section{To the extent that an eligible claim benefits from a statutory or contractual} privilege, it is recommended that the restructuring of such claims take place outside the SDRM.

\section{Trade credit}

66. In practice, it may be desirable to exclude trade credit from the restructuring process. Establishing a formal exclusion under the SDRM could be problematic, however, in light of the difficulty in drawing a clear and workable differentiation between trade and financial credits. A formal exclusion of trade credit from the mechanism in all cases would provide strong incentives for circumvention. Moreover, in extreme cases, it may be necessary to bring trade financing within the scope of a restructuring, as happened on occasion in the 1980s debt crisis. It should be noted that the trade credit to be included under the SDRM will be limited by virtue of the exclusion of most public enterprises. Trade credit falling within the scope of the SDRM is likely to be numerically significant in cases in which it has been guaranteed by the sovereign, and where the guarantee has been called as a result of a default.

67. Accordingly, although it is unlikely that trade credit will be restructured, it is recommended that the SDRM be designed in a manner that it can be used for this purpose when necessary.

\section{Domestic debt}

68. While it is generally recognized that domestic debt may need to be restructured, most Executive Directors have expressed the view that members already have the legal tools to restructure these instruments, at least to the extent that they are governed by domestic law and subject to the exclusive jurisdiction of domestic courts. Even if such claims were to be restructured outside the mechanism, however, the transparency requirements of the SDRM

12 This is also supplemented by negative pledge clauses in bond contracts and bank loan agreements. 
(discussed below) would serve to help ensure that the restructuring of these claims is adequately coordinated with the restructuring of claims under the mechanism. More generally, a number of Executive Directors have stressed that the Fund should avoid encouraging sovereign debtors to use sovereign powers to unilaterally restructure domestic claims unless an overall restructuring process is underway that has the support of the international community. Feedback from market participants highlighted the importance they attach to ensuring that domestic debt is covered by a restructuring, but indicated their support for such restructurings to be conducted outside — but in parallel with — restructurings under the SDRM.

69. As noted earlier, eligible claims will include court judgments requiring payment for liability on eligible claims. As noted above, eligible claims would exclude claims that are governed by domestic law and subject to the exclusive jurisdiction of the domestic courts. However, where a claim governed by domestic law and subject to the exclusive jurisdiction of the domestic courts is recognized and enforced by a court outside the territory of the sovereign, such a claim would be treated as an eligible claim for purposes of the SDRM.

70. In light of the above, it is recommended that claims governed by the domestic law of the sovereign and subject to the exclusive jurisdiction of its courts be restructured outside the SDRM.

\section{Identity of the Creditor Holding the Claim}

71. Notwithstanding the broad scope of the proposed definition of debt covered by the SDRM, some forms of indebtedness could be excluded from the coverage of the mechanism on account of the identity of the holder of the claim. It is proposed that claims of the following creditors be excluded from the mechanism.

\section{International organizations}

72. Claims against the sovereign that would otherwise fall within the definition of "eligible claims" (as discussed in the previous sections) could not be restructured under the SDRM if the creditor were an international organization. Although this exclusion would not legally preclude the debt held by these organizations from being restructured outside the SDRM, it is not envisaged that this would occur. The international architecture provides for multilateral financial institutions to extend financing to sovereigns on a preferred basis. The Fund provides balance of payments support to allow members to adjust without resorting to measures that are destructive to national and international prosperity. Such financing is catalytic, and may be provided while policies take hold and confidence builds and before private creditors resume financing. By the same token, multilateral development banks provide both adjustment lending and financing for investment in human and physical capital at lower costs than could be obtained from international capital markets. The financing of such public goods and capital formation promotes both financial stability and economic growth, and thereby enhances the value of private creditors' claims. The 
ability of these institutions to provide financing at the current cost structure depends critically on the assurance that their claims would not be captured in a sovereign debt restructuring.

73. Although the provisions of the SDRM could contain a list of the existing organizations that would be excluded for this purpose, it could also set forth a definition of the type of organizations to be excluded, thereby providing some degree of flexibility so as to accommodate new organizations that may be established in the future. ${ }^{13}$

\section{Official bilateral creditors}

74. During the most recent discussions, the preliminary view of the Executive Board was that official bilateral claims should be excluded from the SDRM, at least initially, but that close coordination would be needed between Paris Club and SDRM restructurings. Nevertheless, the private sector has expressed the strong view that inclusion of official bilateral creditors within the SDRM - albeit as a separate class - would be critical if the SDRM is to establish a framework that provided for greater inter-creditor equity. The private sector has also expressed a concern that Paris Club restructurings may not address the sustainability of a sovereign's debt since it typically deals only with a window of claims falling due, rather than with the stock of debt, and, for that reason, often relies on repeated reschedulings.

75. If official bilateral creditors were to be covered under the SDRM, they would need to be included as a separate class that would be pre-specified in the text of the amendment. As a separate class, official bilateral creditors could receive terms that differ from those offered to the private sector so long as both creditor groups accepted them. Thus, it would be possible for the official bilateral creditors - through the Paris Club process - not to give debt reduction (given the budgetary implications for such creditors) in cases where the private sector was prepared to agree to reduce its own debt. Bringing the claims of official bilateral creditors within the scope of the SDRM (albeit as a separate creditor class) would likely have the effect of requiring a member seeking to use the mechanism to have a Fund arrangement in place, as this is a prerequisite for a Paris Club restructuring.

76. However, and as was recognized by the Executive Board when this question was last discussed, the inclusion of official bilateral creditors under the SDRM as a separate class would require the resolution of a number of difficult issues:

\footnotetext{
${ }^{13}$ The fact that an otherwise eligible claim benefits from a guarantee extended by an international organization would not, in and of itself, result in an exclusion of the underlying claim from the SDRM. However, to the extent that the guarantee is called by the creditor, the resulting claim of the international organization against the sovereign would be excluded from the SDRM.
} 
77. First, the SDRM would need to operate in a manner that allows for a sequenced restructuring, where necessary. Most importantly, in cases where an agreement between the sovereign and its external creditors will take time, a process would need to be put in place that ensures that any delay in agreement does not prevent Paris Club creditors from resuming normal export cover.

78. Second, how would the qualified majority-voting framework apply to official bilateral creditors? Under its current system, the Paris Club takes its decisions by consensus rather than by a vote. While one could design the SDRM to provide that a consensus would be needed from the class of official bilateral creditors for a restructuring to be approved, such an approach would raise a separate issue: the role of non-Paris Club official bilateral creditors. Since these creditors would form part of the class, any impairment of their claims would require their participation in the decision making process. In these circumstances, it may be necessary to rely on some form of qualified majority voting threshold.

79. Third, which decision of official bilateral creditors would be binding under the SDRM? The Agreed Minute of the Paris Club is a statement of intention by representatives of official creditors to recommend a restructuring to their authorities. The restructuring is only given legal effect once the bilateral restructuring agreements are signed. In order for the Agreed Minute to be given legal effect as a creditor decision under the SDRM, it would be necessary for official bilateral creditors to cede this authority to their Paris Club representatives. Maintaining the existing two-step decision structure under the SDRM would most likely mean that private creditors would not be willing to legally bind themselves until this second step was taken.

80. As discussed in the previous paper, an alternative approach would be to exclude official bilateral creditors from formal inclusion under the SDRM but establish a procedure that would ensure that there was sufficient coordination between these two restructuring frameworks that inter-creditor equity issues are adequately addressed. The features of the SDRM itself assist in that respect. First, the transparency requirements discussed in the subsequent sections of this paper would ensure that private creditors would have adequate knowledge of the sovereign debtor's treatment of official bilateral creditors when it makes a restructuring proposal. Second, to the extent that the SDRM catalyzes coordination of private creditors, including through the creation of creditors' committees (discussed in a subsequent section), it will enhance the ability of private creditors to engage in a dialogue with official creditors. If this second approach were to be followed, additional principles and procedures would need to be developed jointly by private creditors and official creditors to address coordination and sequencing issues.

81. Whether official bilateral claims are excluded or included as a separate class, a number of definitional issues arise. Presumably, official creditors would include not only the claims held by governments but also claims held, guaranteed or insured by certain (but not all) agencies, such as export credit agencies. Of course, eligible claims held by an entity controlled by the sovereign debtor would not be excluded from restructuring under the SDRM, although they would be excluded from the voting process (see Section VI below). 
However, claims on the sovereign debtor, once purchased by the sovereign debtor itself, would cease to be regarded as liabilities of the sovereign debtor.

82. Finally, and more generally, it is important to emphasize that the special treatment of official bilateral claims (whether in the form of exclusion or as a separate class) would be based on the fact that the claim is held by the official creditor during the restructuring process - it would not be based on the fact that it originated as an official bilateral claim. In the event that an official bilateral creditor was to sell a claim against a sovereign to a private creditor, such a claim would become an eligible claim under the SDRM. This approach would ensure that, in the event that these claims are purchased by vulture creditors, the SDRM could be used to prevent disruptive litigation.

83. In light of the above, a critical question is whether the claims of official bilateral creditors will be restructured outside the SDRM or, alternatively, will be restructured within the SDRM as a separate class.

\section{Activation}

84. The SDRM could only be initiated by the sovereign debtor. Should any conditions be imposed on its ability to do so? As has been discussed in the initial section of this paper, the SDRM is intended to be used in circumstances where a member's debt is unsustainable. Accordingly, it would seem appropriate for the text of the amendment to state, in general terms, that the mechanism is being established to assist members whose debt is unsustainable. The question arises, however, as whether this general statement of purpose should also be enforced as a condition for activation and, if so, by whom?

85. When addressing this question, it should be recognized that the Fund, through the exercise of its existing financial powers, will often influence a member's decision as to whether and when it will activate the mechanism. In particular, this decision will be influenced by judgments made by the Fund about the scale of the financing it would be willing to provide in the absence of a debt restructuring and the magnitude and feasibility of domestic policy adjustment.

86. There may be cases, however, where a member may wish to activate the SDRM even though the Fund does not believe that the member's debt is unsustainable. Informal consultations with emerging market representatives reveal a concern that, following the establishment of the SDRM, it may be more difficult to resist domestic political pressures to activate the mechanism in cases in which the member's debt situation is sustainable; e.g., where payments difficulties relate to either liquidity constraints or the debtor's willingness to cease making contractual payments because of a change in domestic priorities.

87. In light of the above, one approach would be to give the sovereign the right to activate the mechanism unilaterally but to design the mechanism in a manner that minimizes the incentives for unjustified activation. While the sovereign would formally represent that its debt is unsustainable when it provided notice of activation, activation would be automatic 
when such a notification is received - there would be no need for an independent confirmation as to the accuracy of the member's representation. A member would obviously be free to consult with the Fund before activating the mechanism, but would not be required to do so. Clearly, in deciding whether to support the authorities' proposals under the mechanism, creditors would need to take into account their own assessment of the debtor's debt situation, and this fact would also be taken into account by the debtor before it activates.

88. Whether the unilateral right to activate will create incentives for unjustified use will depend, in large part, on the consequences of activation. For example, to the extent that features of the mechanism greatly enhance a debtor's legal leverage over its creditors, the risk of unjustified use would increase. However, as will be discussed in detail in the next section, it is not proposed that the features of the mechanism would provide debtors with such leverage. Specifically, activation will set in motion a procedure that will facilitate creditor organization and voting - it will not automatically trigger an automatic stay or any other interference with contractual relations. Moreover, and as discussed below, where creditors themselves have formed the view that activation was unjustified, they could vote to terminate the mechanism once they are in a position to cast such a vote; i.e., when their claims have been registered and verified.

89. Nevertheless, since the SDRM would enable a debtor to bind all of its creditors to a restructuring agreement through the vote of a qualified majority, it does present some benefits for the sovereign debtor. Moreover, even though a member's debt may not be sustainable prior to activation, the decision by the debtor to use the mechanism may itself make the debt unsustainable, at which point the debtor could make use of the majority restructuring provisions to its advantage.

90. In light of the above, an alternative approach would be to require that, as a condition for activation, a party other than the member would need to conclude that the member's representation of unsustainability is not entirely unjustified. The difficulty with this approach is identifying an appropriate party to play this role. Although the Fund is uniquely qualified to perform this function, this would enhance its role and legal authority under the mechanism. Apart from expressing concerns regarding the Fund's general impartiality, some private market participants have signaled that they doubt the value of a Fund endorsement for activation in light of the perception that the Fund's judgment on sustainability in individual cases may be colored by considerations of political economy. Of course, even if the Fund did not perform this role, it would not be indifferent to an unjustified activation. In such circumstances, it could decide that all costs arising from the use of the SDRM (including the operation of the Sovereign Debt Dispute Resolution Forum (SDDRF)) would be borne by the debtor and, therefore, would become a liability of the member to the Fund in the General Resources Account. This latter feature could provide an appropriate means for the Fund to signal its disapproval of the activation.

91. Giving creditors this role would present its own difficulties. First, creditors would not be able to express a collective view through a vote until their claims were registered and verified, which would take place after activation. While this authority could conceivably be 
given to a creditors committee, such an approach would likely give rise to delays and uncertainty given the likelihood of disputes as to whether the committee is sufficiently representative. More generally, providing creditors with a veto on activation may give them excessive leverage in circumstances where a member's debt is, in fact, unsustainableleverage that could be used to place further pressure on the Fund to provide financing.

92. Accordingly, a critical issue for further discussion is whether it is necessary to provide an independent confirmation of the member's representation of unsustainability as a condition for activation and, if so, who should perform this function.

\section{Consequences of Activation}

93. Once activated, the SDRM must set in motion a procedure that will enable the debtor and a qualified majority of its creditors to be in a position where they can make key decisions that can bind all eligible claims.

94. Ideally, a member will have both entered into and completed its negotiations with its creditors before having activated the mechanism, during which time it may try to stay current on all of its obligations. In these circumstances, the SDRM will be used solely for the purposes of making the agreement that the member has reached with the qualified majority binding on the entire creditor body. In this sense, the member's negotiations will benefit from the "shadow" of the SDRM: potential holdouts will be more reasonable during the negotiations since they will know that, if they are inflexible, the debtor and creditors will be able to use the mechanism to bind them to an agreement. In these circumstances, the procedure discussed in the first part of this section will unfold rapidly. Indeed, the primary purpose of the registration and verification procedure would be to confirm that the creditors supporting the agreement do indeed represent a qualified majority.

95. Not all sovereign members will have been able to conclude negotiations prior to activation. The second and third parts of this section are intended to primarily address these situations. Specifically, the second part analyses whether, upon activation, it would also be appropriate for the mechanism to provide for a stay on creditor enforcement, either automatically or upon a vote of a qualified majority of creditors, during the negotiation period. In that context, the third part assesses the advantages and disadvantages of providing for a suspension of the operation of certain contractual provisions for a temporary period following activation. The final portion discusses other possible consequences of activation.

\section{A. Provision of Information, Registration and Verification}

96. If the SDRM is to achieve its objective, there must be a procedure that enables the debtor and creditors to make timely decisions on the basis of all material information. For example, when creditors vote on a restructuring proposal, they must have confidence that they have an understanding of not only the debtor's total outstanding indebtedness but also of how such indebtedness is going to be treated under the proposed restructuring. Moreover, 
they must also have some assurance that the voting process is not being manipulated. As will be discussed further below, this will be of particular concern given the fact that claims will be aggregated for voting purposes. For both debtors and creditors alike, it is also imperative that any procedure provide adequate incentives for a rapid restructuring. An overly protracted process will only undermine the value of claims to the detriment of all concerned.

97. The proposed procedure set forth below is designed to achieve the above objectives and comprises three related components: (i) provision of information, (ii) claims registration, and (iii) claims verification. Each is discussed in turn.

\section{Provision of information}

98. As discussed in the previous section, not all claims would be restructured under the SDRM. Nevertheless, the information requirements established under the SDRM would be designed to ensure that creditors holding eligible claims have access to all information regarding the sovereign's indebtedness - including debt to be restructured outside the mechanism - so that their own decisions are adequately informed. The procedure set forth below would be intended to achieve this objective.

99. Once the conditions for activation have been met, the SDDRF would arrange for the immediate publication of the Activation Notification. Although the form of publication would be set forth in administrative rules adopted by the SDDRF, the text of the amendment (or the associated commentary) would specify that the media of publication must be such that adequate notice is provided on a global level, taking into account all available technology.

100. Within a specified period following the date of the SDDRF's receipt of the Activation Notification, the sovereign debtor would provide to the SDDRF all known information regarding its indebtedness ("Claims Notification"). Moreover, to the extent that the debt of other debtors is to be restructured under the SDRM (e.g., the debt of the central bank or a subnational government), this debt would also need to be included. ${ }^{14}$ The Claims Notification would be organized into the following lists:

101. The first list would consist of the subset of eligible claims that the sovereign intends to restructure under the SDRM ("SDRM Restructuring List"). Claims included in this category would be identified in as specific manner as possible and would include the date on which the claim arose, its face value, due date and the identity of the creditor of record. It is recognized that, in some cases, the sovereign debtor may no longer have detailed information of all the debt that it intends to restructure. This problem could arise, for example, in circumstances where the sovereign would have suspended payments for a protracted period.

${ }^{14}$ As with the notification, the period within which the member would need to provide this information would be specified in procedural rules to be adopted by the SDDRF. 
102. The second list would include all claims other than eligible claims that the sovereign debtor intends to restructure outside the SDRM ("Non-SDRM Restructuring List").

Depending on the scope of debt to be covered under the SDRM, this could include all those claims of the Paris Club or domestic claims which the sovereign intends to restructure outside the SDRM. This list could be less detailed but would, at a minimum, identify the essential terms of the debt and its aggregate value.

103. The third list would include all other claims, i.e., claims that the sovereign does not intend to restructure ("Non-Impaired List"). This list would be comprised of: (i) eligible claims that the sovereign would be proposing to exempt from the specific restructuring and (ii) all other claims that are excluded from sovereign debt restructuring more generally; i.e., claims of multilateral organizations. This list could also be of a more general nature, and would identify claims by category (e.g., supplier's credits) with an aggregate value for each category.

104. The above lists would evolve as the restructuring process advances. For example, the SDRM Restructuring List may expand as a result of changing economic circumstances. Moreover, for reasons of intercreditor equity, creditors that find themselves on the SDRM Restructuring List may insist that, as a condition for their support, certain eligible claims be moved from the Nonimpaired Claim List to the SDRM Restructuring List. Finally, the Nonimpaired List would expand to the extent that new financing is provided by either international organizations or by creditors that have been given priority pursuant to a vote by a qualified majority (see Section VII below).

105. The Claims Notification would be made available for inspection through a website established by the SDDRF. As with the Activation Notification, the treaty would not specify the media of publication; such rules would be promulgated by the SDDRF.

\section{Registration}

106. All creditors holding eligible claims that are included on the SDRM Restructuring List would be required to register their claims with the SDDRF within a specified period if they wished to vote on any of the proposals made by the sovereign debtor (these proposals are discussed in Section VII below). Failure to register within the time period would not mean, however, that a creditor holding a claim that appears on the SDRM Restructuring List would be excluded from the terms of the restructuring. As discussed in greater detail below, such "sleeping claims" would be treated as registered claims for restructuring purposes for a defined period after the final restructuring agreement is certified by the SDDRF. After that period, however, any claims that appeared on the SDRM Restructuring List that had not been registered could be treated as null and void. Alternatively, their legal status would be determined by each member's statute of limitations.

107. The above approach would create incentives for both the sovereign debtor and creditors to disclose all relevant information regarding the existence of claims on the sovereign on a timely basis. Since the only claims that could be restructured under the SDRM 
would be those that appeared on the SDRM Restructuring List, the sovereign would have an interest in ensuring that this list is as complete as possible. At the same time, since creditors holding claims on the SDRM Restructuring List would recognize that they have nothing to gain from "sleeping" through the process, they would register so as to participate in the voting process.

108. To register its claim, a creditor would identify itself as the holder of the claim in question and state the value of its claim. To the extent that the claim is secured, the creditor would also need to submit information regarding the value of the collateral as of the date of submission. As will be discussed further below, although secured claims would not be subject to much of the restructuring process, the debtor may place a secured creditor on the SDRM Restructuring List to the extent that the creditor is undersecured; i.e., the value of the collateral is lower than the face value of the claim. As is discussed below, a critical question is whether the creditor that registers the claim is the creditor of record or the end investor.

109. The text of the amendment would specify the period within which creditors would need to register. This period would run from the date on which the Claims Notification is published (or amended as a result of subsequent additions) and would need to be sufficiently long to provide creditors with ample opportunity to submit the supporting documentation (at least 30 days).

110. The registration process would need to accommodate secondary market trading of eligible claims. To the extent that the holder of a registered claim transferred its claim, the transferee would be required to register as the new holder of the claim in order for it to be eligible to participate both in the voting process and in any restructuring agreement that is eventually certified by the SDDRF.

\section{Verification}

111. Claims that have been registered will be considered as a verified registered claim unless they are challenged by the sovereign debtor or a holder of an eligible claim within a specified period (perhaps 30 days) after the date of registration. The rules of procedure of the SDDRF will need to be designed to ensure that disputes regarding the validity or value of claims are resolved in a timely manner. Unless the disputes are resolved in an expeditious manner, the voting process will be subject to considerable delays. At the same time, for the verification process to be effective, it must address two very different situations.

112. First, the sovereign may dispute the claim submitted by the creditor. Challenges raised by the sovereign will be limited by the fact that the scope of all registered claims will be originally defined by the list provided by the sovereign who will therefore not be in a position to challenge the existence of the claim. However, it may dispute the value of the claim submitted by the creditor, including the value of the collateral.

113. Second, creditors may dispute the validity of claims submitted by other creditors. In particular, in circumstances where claims are aggregated for voting purposes, creditors may be concerned that the sovereign has created fictitious claims. To the extent that a sovereign 
issues securities or makes a private placement to an entity that it owns or controls and does not receive any value from that entity when issuing that claim, it can distort the restructuring process in two ways. First, those claims, once registered, can be voted in a manner that would support onerous debt restructuring terms for holders of valid claims. Second, since these claims would be recognized under any restructuring agreement, they would reduce the amount to be received by valid creditors.

114. In order for the verification process to be effective, the question arises as to whether the creditor registering a claim must be the end-investor or, alternatively, may be the lender of record. Under current market practice, private settlement companies and their depositories, who are the lenders of record for voting purposes, hold public securities issued by a sovereign in a global form. The beneficial owners of the securities normally have accounts with large financial institutions that, in turn, have accounts with these settlement companies. In the context of the SDRM, creditors may not be in a position to meaningfully challenge the validity of a claim unless they know the identity of the end-investor.

115. The problem of creditor identification during the verification process is closely related to the problem of identifying related parties during the voting process. As has been discussed in earlier papers, the SDRM would preclude creditors from voting in the event that there is evidence that: (i) the creditors are under the control of the sovereign or (ii) undue influence has been placed by a sovereign on a creditor to vote in a particular manner. Unlike the problem of fictitious claims, claims held by "related parties" would be valid and would be recognized as such under the eventual restructuring plan. However, they would be excluded from the voting process so as to ensure that the sovereign could not manipulate the vote. At any time prior to - or for a defined period after - a vote, creditors would have the right to request the SDDRF to exclude a creditor from the vote on the above grounds.

116. One approach to both of the above problems would be to require end-investorsrather than the lenders of record - to register their claims. Of course, this step would not, on its own, provide creditors with all the information they would need to have in order to determine whether it was necessary to challenge a claim for verification or voting purposes. The sovereign could always establish a special purpose vehicle as the end-investor. With respect to the problem of voting by related parties, it also needs to be recognized that aggregation may actually make it more difficult for the sovereign to distort the voting process, particularly if the claims eligible for restructuring under the SDRM exclude claims governed by domestic law. While it may be possible for the sovereign to exert enough influence over domestic banks and other domestic entities to effect the voting of a single issuance, it will be more difficult for it do so when all foreign law instruments are aggregated.

117. In any event, the SDDRF would need to adopt rules of procedure to handle disputes arising from the voting process. As noted earlier, claims submitted or votes cast would be considered valid for verification and voting purposes unless the claim or the vote has been challenged. Once challenged, the SDDRF could adopt procedures that required the challenged creditor to produce evidence that adequately demonstrates that the claim and vote 
is otherwise consistent with the rules of the mechanism. To the extent that the creditor does not produce adequate evidence to that effect, the claim or the vote (as the case may be) would not be recognized. If this procedure were adopted, the only question would be whether or not disclosure of the end-investor during the initial claims registration stage would be a necessary means of providing creditors with adequate information to determine whether a challenge is necessary. To address problems arising from votes being cast by creditors that are controlled by the debtor, the debtor could certify that it is not aware of any voting creditor that would violate this prohibition. Creditors could also provide such certifications.

118. As noted above, new claims may need to be added to the SDRM Restructuring List as the process advances, either because of changes in the economic environment or because creditors have requested such additions for inter-creditor equity purposes. These claims would also be vetted through the registration and verification procedure described above.

119. How long would it take before creditors are in a position to vote on the debtor's proposal? To the extent that the debtor has already completed negotiations prior to activation and, accordingly, where the existence and value of claims had already been stipulated, the procedure could be completed very rapidly. In essence, the restructuring proposal would be submitted for a vote immediately upon activation. The vote could take place provided that, within the minimum verification period, no challenges had come to light that called into question whether the creditors that had indicated support did, in fact, represent a qualified majority of all registered claims that appear on the SDRM Restructuring List. In the nonsovereign context, complex restructurings that have been "pre-negotiated" before commencement of formal proceedings have been voted on within 45 days of commencement. One could envisage the SDRM catalyzing the creation of standing private organizations that would assist in pre-registering claims prior to activation.

120. However, in circumstances where the debtor has not approached its creditors prior to activation, the period would be longer. Measures would be introduced, however, to expedite the process. Where, following activation, the debtor had reached an agreement with what it believes to be the necessary threshold of creditors to make a decision, it could request a vote even though the verification process had not been completed for a certain group of claims that are still under dispute. Drawing upon practices that are used in the nonsovereign context, an affirmative vote by the necessary threshold could become effective as long as the aggregate value of the remaining disputed claims was not sufficient to bring the vote below the minimum acceptance threshold (on the assumption that they would have voted against the proposal).

121. Finally, it should be noted that, since the SDDRF would be a forum that would be dedicated exclusively to the resolution of disputes that arise in this context, it would be in a position to resolve these disputes in a timely fashion. Of course, it must be recognized that there will be cases where the registration and verification may become protracted.

122. A graph illustrating how the information, registration, verification and voting procedure would unfold is set forth in the Appendix. 


\section{It is recommended that the SDRM incorporate the general features of the} information, registration and verification procedure described above. However, a key issue to be resolved is whether it is necessary for end-investors to register in order to control abuse of the mechanism.

\section{B. Stay on Enforcement}

124. There may be circumstances where a sovereign debtor defaults on its external debt either before or shortly after activation. While in some cases it may have made progress in its negotiations with creditors prior to activation, in other cases the process may not have begun. A key question in the design of the SDRM is whether it should provide for a stay on creditor enforcement, either automatically upon activation or upon an affirmative vote by a qualified majority of creditors. Perhaps more than any other issue, this feature of the proposed mechanism has generated considerable controversy. The views of many market participants is that a generalized stay would constitute a significant erosion of contractual rights in an environment where contractual rights against a sovereign are already quite fragile. While many of these participants have acknowledged that subjecting the activation of a stay to an affirmative vote of a qualified majority of creditors would be a preferable alternative, they are of the view that any generalized stay on enforcement would still be an unnecessary interference of contractual claims, particularly given the limited history of sovereign litigation.

125. Consistent with the principles identified in the first section of this paper, an assessment of the merits and design of a stay on enforcement must take into consideration whether its absence would severely undermine the capacity of the debtor and its creditors to reach a rapid restructuring agreement. In making this assessment, it is necessary to take into account the differing positions of unsecured and privileged creditors.

\section{Unsecured Creditors}

126. For the unsecured creditor, its ability to disrupt the process though legal action immediately following a default is limited. Once a creditor chooses to accelerate its claim following a payment default, it may initiate legal proceedings to obtain a court judgment for the full amount of the debt. If such a judgment on liability is awarded, the creditor may proceed to attach available assets of the sovereign or to obtain court orders directing repayment by the sovereign (which potentially could interfere with transactions between the sovereign and other creditors). Prior to obtaining a judgment, the litigating creditor may also seek a pre-judgment attachment order in certain jurisdictions. However, the ability of creditors to initiate legal proceedings and to enforce judgments against sovereigns is subject to the constraints of the varying national procedural rules, including those on sovereign immunity. These procedural rules can present significant obstacles to litigating creditors, 
requiring substantial expenditure of resources in litigation towards highly uncertain recovery. 15

127. To date, the most disruptive creditor litigation has been pursued after a restructuring agreement has been reached: once a critical mass of creditors has reached an agreement, a holdout creditor (normally one that has purchased his claim on the secondary market at a steep discount) will engage in aggressive legal tactics, with the knowledge that it will not have to share the proceeds of any litigation with other creditors that have already surrendered their original claims.

128. The effect of the SDRM may change this dynamic. Faced with the prospect of a process involving a restructuring agreement that can be made binding on all creditors, creditors may consider that they have a limited window of opportunity to enhance their position through litigation. Creditors might therefore decide to initiate litigation immediately upon a default. The goal of the litigation would be, prior to imposition of a stay, either to have obtained repayment with the aid of national judicial (or arbitral) processes or at least to have attained the status of a secured creditor by virtue of obtaining a judicially ordered collateral on the sovereign's assets. ${ }^{16}$ The risk is that the non-imposition of an automatic stay would fuel the race to the court house among unsecured creditors and result in a highly disorderly period.

129. At the same time, however, the aggressive litigant would need to take into consideration the risk that creditors may organize quickly and agree to a restructuring agreement before the litigant has been able to enforce its claims. Since judgments arising from contractual claims would be subject to the SDRM, a creditor who has managed to obtain a judgment - but has not yet collected on it - could still have its claim restructured through a vote of a qualified majority. Accordingly, a litigating creditor could only avoid being subject to the operation of the SDRM if it were able to obtain a judgment and satisfy this judgment (through, for example the attachment of assets) prior to the sovereign reaching an agreement with its creditors. Given the expense of litigation, this uncertainty may pose an important deterrent on litigation.

${ }^{15}$ Furthermore, given the commonly-held legal principle that the liabilities of the sovereign are not attributed to separate entities, such as independent central banks, reserves held by the central banks would normally be unavailable for satisfaction of claims against the sovereign. In addition, by depositing assets in jurisdiction or institutions (such as the BIS) that recognize or enjoy enhanced protections from legal process, the sovereign debtor may be able to further limit its vulnerability to creditor litigation.

${ }^{16}$ There would be no advantage to the creditor that has initiated litigation and only obtained (an unsatisfied or uncollateralized) judgment on liability upon activation of the stay. Such a judgment creditor is in the same position as other unsecured creditors in terms of being subject to the stay. 
130. On the basis of the above analysis, to what extent is it necessary for the SDRM to provide for a stay and, if so, how should it be designed? On balance, while there is a risk that creditor enforcement prior to the reaching of an agreement could undermine the restructuring process, the imposition of a generalized stay (whether automatically or through a vote by the qualified majority) may not be the most effective way of addressing this risk for the following reasons.

131. First, one of the principal difficulties with enabling the sovereign to impose a stay on enforcement immediately after activation is that it would not be accompanied by a general cessation of payments. Under most insolvency laws, a stay on creditor enforcement is of general applicability and is accompanied by a requirement that the debtor not make payments to any pre-petition creditors. Together, the stay on enforcement and the cessation of payments put in place a "standstill" that ensures intercreditor equity. As described in the first portion of this section, however, it is very likely that the sovereign will wish to exclude certain eligible claims from the restructuring process and continue to make payments to them during the restructuring process. If the SDRM is to give the sovereign this needed flexibility, there are strong reasons why a stay on enforcement on unpaid claims should only be put in place by a vote of the creditors affected. When casting their votes, these creditors would be in a position to take into consideration whether the exclusion of certain forms of debt from the restructuring process is - in their view-justified.

132. Second, while conditioning the activation of the stay on an affirmative vote of a qualified majority may address the above limitation, it raises other problems. Since, as discussed in the previous section, it will take some time before creditors are in a position to take any decisions that involve the aggregation of claims, there would inevitably be a delay in the activation of this stay, during which time disruptive litigation may take place. Moreover, consultations with market participants and representatives of both the legal and judicial professions evidence a concern that a generalized stay on all enforcement, even if subject to a vote, may be unnecessarily intrusive given the fact that the risk of severely disruptive litigation prior to a restructuring is somewhat limited.

133. In light of the above, consideration could be given to introducing alternative measures that would have the effect of deterring disruptive litigation from the moment of activation but would not involve the imposition of a general stay on enforcement. Drawing on principles developed in the nonsovereign context, one such measure would provide as follows: Any creditor that had managed to partially satisfy its claim through judicial enforcement after activation but prior to the restructuring agreement would automatically have the value of its residual claim reduced under the restructuring agreement in a manner that ensures that all of the benefits of its enforcement and collection have been neutralized. ${ }^{17}$ In these circumstances, the creditor would have borne the considerable expense of legal action for no benefit.

${ }^{17}$ By way of example: a creditor possessing a claim with a face value of $\$ 10$ million manages to seize assets worth $\$ 4$ million through judicial enforcement. Under the terms of 
134. The advantage of this approach (which, as described in Box 1, is referred to as the "hotchpot" rule in the nonsovereign context) is that would discourage litigation without imposing a limitation on enforcement rights. In this respect, it would be tailored to address the problem of disruptive litigation from an inter-creditor-rather than a debtor vs. creditorperspective. Creditors exercising forbearance would have some assurance that litigation prior to the restructuring would not provide an undue advantage to the litigant. Moreover, the rule would only go into effect if they actually reached a debt restructuring agreement.

135. The approach has limitations, however. Most importantly, to the extent that the judgment creditor is able to obtain more through litigation than what it had received under the agreement, the above rule could not be applied.

136. As a means of addressing this limitation, consideration could be given to introducing an additional measure that would further discourage litigation, but in a very targeted manner. The SDRM could provide that, upon the request of the debtor, the SDDRF would have the authority-but only with the approval of creditors- to issue an order that would require a court outside the territory of the sovereign to enjoin specific enforcement actions if a determination was made that such actions seriously undermined the restructuring process. Circumstances where such an order would be warranted would include, for example, situations where there is a risk that creditors may attach assets of a sufficient value that they could circumvent the operation of the above "hotchpot" rule. By being limited to specific enforcement actions, it has the advantage of being less intrusive than a generalized stay.

137. The drawback of this option is that it is difficult to design an effective means of obtaining creditor approval, which would be an essential condition for its application. Although a vote by a qualified majority could be considered, this would necessarily involve a delay, as discussed above. An alternative approach would be to confer this authority on a representative creditors' committee between the time when the committee is formed and the

the eventual restructuring agreement, all unsecured creditors receive a combination of cash and new securities with a secondary market value at the time of issuance of 50 percent of the original face value of their claims. Under the approach suggested, the judgment creditor would receive only $\$ 1$ million; i.e., the 50 percent of its original claim, as further reduced by the full amount of the recovery. Without such a "hotchpot" provision, the judgment creditor would receive \$3 million under the restructuring agreement (i.e., 50 percent of the unsatisfied proportion of the judgment). 


\section{Box 1. Derivation of Hotchpot Rule}

The hotchpot rule is derived from the cross border insolvency law context. Cross border insolvency proceedings present opportunities for some creditors to satisfy part of their claims through actions in a number of jurisdictions. Through such multiple actions, creditors could augment their recovery and obtain greater recovery relative to the creditors that limit their participation to only one proceeding. The hotchpot rule is designed to counter such creditor actions and to maintain inter-creditor fairness across creditor claims that are subject to multiple jurisdictions.

\section{Operation of English law hotchpot rule}

The hotchpot rule was devised in nineteenth century English bankruptcy law. This rule generally operates when a creditor receives satisfaction of part of its claim in another jurisdiction after the commencement of English bankruptcy proceedings and then lodges a proof of claim for the deficiency in an English bankruptcy proceeding. The general effect of the hotchpot rule is that the precipitous creditor is only entitled to receive a dividend in the English proceeding after full credit has been given for the value of the creditor's recovery. Consequently, if the percentage of the creditor's recovery exceeds that available in the distribution, that creditor will be excluded from participating in the English bankruptcy proceeding.

Application of the English law hotchpot rule is limited against creditors with valid security interests that pre-date the commencement of the English proceedings. Such secured creditors are entitled to claim for any deficiency after deducting their recovery on collateral abroad realized after commencement of the English proceeding. The English hotchpot rule thus recognizes the privileged position of secured creditors so long as they obtained that status prior to the commencement of English proceeding. (Other rules on stay and voiding of preferential transactions address creditors that seek to convert from an unsecured to a secured status after commencement of the English proceeding.)

\section{Wider adoption of hotchpot rule}

Close variations of the hotchpot rule are now found in the insolvency laws of many jurisdictions (including Canada, the United States, Switzerland and Germany) and in Article 32 of the UNCITRAL Model Law on Cross-Border Insolvency and in Article 20(2) of the European Community Regulation on Insolvency Proceedings (which applies to liquidation and certain rehabilitation proceedings within members states of the European Community and came into effect in May 2002).

\section{Relationship between hotchpot and claw-back}

The hotchpot rule is more limited than rules common in the domestic insolvency realm on voiding or subordinating preferential transactions prior to and after commencement of the insolvency proceeding. However, in the cross-border insolvency context, some laws have gone further than the simple hotchpot rule and in addition enforce equalization among creditors by requiring a precipitous creditor to surrender its recovery gained in other proceedings to the bankruptcy estate for the benefit of the general class of creditors. For example, Article 20(1) of the European Community Regulation on Insolvency Proceedings adopts such a claw back rule (subject to third party rights).

In considering whether a claw-back rule should also be included in the SDRM, two points should be emphasized. First, the principle behind the claw-back rule is that in proceedings involving the compromise of assets and liabilities, creditor equalization should be achieved (or at least individual preferences be neutralized) within distribution of the net bankruptcy estate. Second, an effective claw-back rule requires the exercise of substantial compulsory legal powers. Given the confines of the SDRM in restructuring only the liabilities of the sovereign debtor through a moderately intrusive legal framework, a claw-back rule would be out of place. In contrast, the simple hotchpot rule - with the qualification that it only applies to recovery through judicial enforcement — would be a useful tool consistent with SDRM's design. 
time when a vote of creditors would be feasible and, thereafter, rely on a vote by creditors. ${ }^{18}$ Rules regarding the formation and operation of creditors' committees are discussed in Section VII, below.

138. If this feature is considered, it would be designed to achieve inter-creditor equity among claims that are subject to the mechanism. It would not provide a means by which either a sovereign debtor or creditors that are outside the mechanism could address disruptive litigation. Accordingly, where litigation is initiated by a private creditor against a sovereign debtor that is negotiating a restructuring agreement with official bilateral creditors, these creditors would only be able to take advantage of this feature if official bilateral creditors were subject to the mechanism. In any case, this feature could not be used to address cases where the litigation undermines the debtor's normalization of its relations with international financial institutions.

\section{Privileged Claims}

139. For the creditor whose claim benefits from a privilege (whether in the form of collateral, a right of set-off or otherwise), the situation is considerably different and, for this reason, the above solutions would not be applicable. Upon an event of default, a privileged creditor will be able to exercise its contractual rights to seize the pre-specified assets that secure its claim, an act that it will often be able to undertake without the need for judicial assistance. Where the assets in question secure the full amount of the claim, an acceleration of all amounts due and payable may have an immediate impact on the financial position of the debtor. To the extent that the enforcement of the claim against the collateral further diminishes resources available for future debt service, such action will also be detrimental to unsecured creditors.

140. Notwithstanding the above risks, the introduction of any measures that would stay enforcement by a privileged creditor following an event of default would represent a very significant intrusion on contractual claims. Privileged creditors pay for such privileges (by lowering the cost of credit) precisely because they wish to limit the risk of default. Accordingly, any limitation on the ability of a privileged creditor to enforce its claims following such a default would erode the value of this security. In sum, while an orderly restructuring process provides the most effective means for an unsecured creditor to maximize the value of its claims, a privileged creditor will normally maximize value through

\footnotetext{
${ }^{18}$ For such a feature to be feasible, the amendment would need to provide that neither the debtor nor individual creditors could be made liable in an action brought by the enforcing creditor regarding the damages caused by such an order or the failure to request such an order.
} 
enforcement. For these reasons, consideration could be given to less intrusive measures that could address this problem. These measures are discussed below.

141. On balance, a general stay on enforcement (whether automatic or subject to a vote by a qualified majority) is not a recommended feature of the SDRM. Rather, the implementation of the "hotchpot" rule described above would provide a more appropriate disincentive for litigation. The question arises as to whether such an instrument should be supplemented by a feature that would enable the SDDRF, upon the request of the debtorbut upon the approval of creditors-to issue an order that would enjoin specific enforcement actions in circumstances where such enforcement could undermine the restructuring process.

\section{Contractual Provisions}

142. The analysis contained in the previous section assumed that the member will have to cease making payments either prior to or immediately after the activation of the SDRM. There may be cases, however, where members have activated the mechanism sufficiently early that they will be in position to service their debt during the restructuring process. For these members, the primary question is whether the mechanism should prevent creditors from being able to declare a default even though the debtor is continuing to service its debt.

143. It is very likely that market practice will develop where, once the SDRM enters into force, all sovereign debt contracts will include provisions that will enable the creditor to declare an event of default when the member activates the SDRM (or requests its creditors to take any decisions under the SDRM) — even though the member continues to make payments and is otherwise in compliance with all covenants under the contract. Upon the triggering of such an event of default, creditors will have the right to accelerate their claims; i.e., the full amount of the debt will become due and payable. If creditors were to exercise this right, it would prevent the sovereign debtor from servicing its obligations during the restructuring process. Moreover, to the extent that the sovereign was only intending to restructure a portion of its external debt, the potential acceleration of all eligible claims would make this task far more difficult. Indeed, in cases in which it is evident that not all creditors will be paid in full, creditors with relatively long-term claims may support an interruption in payments so as to prevent those with short-term claims from being able to exit.

144. In circumstances where the creditor benefits from a privilege, the triggering of an event of default will enable it to exercise its rights against the pre-specified assets of the debtor, giving rise to the consequences discussed in the previous section.

145. In light of the above, one could consider designing the SDRM in a manner whereby events of default that are triggered solely as a result of the activation and use of the SDRM would be suspended for a temporary period (perhaps 120 days). Such an approach would be designed to enable the debtor to actually avoid a default on any of its debt after activation as long as it continued to service all of this debt during the restructuring process. In effect, it would neutralize the consequence of activation of the SDRM and would assist the sovereign 
in avoiding the reputation damage associated with a default. Moreover, in the event that the sovereign only needed to restructure a portion of its eligible claims to achieve sustainability, this approach would prevent the activation of the SDRM from triggering an acceleration of all eligible claims. Finally, it would prevent privileged creditors from foreclosing on their collateral provided that all other obligations are being met.

146. Despite the attraction of such a feature, it has important limitations. Most importantly, it could be subject to circumvention. If such a provision were to be introduced, creditors would introduce other events of default that would become effective proxies for activation; e.g., specific debt-to-GDP ratios. Moreover, there may be more effective means of forestalling acceleration where the only event of default arises from the use of the SDRM. In such circumstances, a creditor that is being paid on its claim would most likely only accelerate if it perceived that the advantage of acceleration outweighed the drawbacks. The key drawback is that, for a creditor who is being paid, an acceleration will trigger an event of default. The key advantage of acceleration is that it an accelerated claim may be perceived as giving the creditor leverage in the negotiating process. As will be discussed in Section VII of the paper, such an advantage - and, therefore, the incentive to accelerate -could be effectively neutralized by a provision that would enable the debtor to reinstate, in the context of the restructuring agreement, the maturity of the original instrument provided that all other events of default are cured.

147. A more robust suspension of contractual provisions would be one which prevents a declaration of default after the activation of the SDRM unless the creditor had not been paid. Accordingly, in circumstances where the sovereign debtor has not been able to pay certain creditors but wishes to pay others, this approach would prevent a default on one creditor from triggering the cross-default clause of a creditor that is continuing to be repaid. This approach may be particularly valuable in circumstances when a debtor has defaulted on its unsecured indebtedness but wishes to continue to service its debt to a privileged creditor so as to avoid the seizure of important assets. As with the first approach, the suspension of these clauses would be temporary. Unlike the first approach, however, it would be more difficult to circumvent since the only event of default that would provide a basis for enforcement would be a payment default.

148. A key purpose of the above measure would be to enable the sovereign debtor to continue to prevent a default on unsecured debt from triggering an event of default on secured debt. If the debtor paid the secured creditor on its original claim, the secured creditor could not exercise self-help enforcement measures. Such a measure would, nevertheless, constitute an important interference with contractual enforcement, particularly since it would nullify the operation of other covenants that would otherwise give rise to a default. Applying the principle identified in the initial section of the paper, the question arises as to whether such an interference provides a necessary means of safeguarding the restructuring process. Stated differently, without such a measure, would the privileged creditor exercise its acceleration and enforcement rights if it is still being paid? The answer to this question depends, in large part, on whether the privileged creditor has reason to believe that there is a risk that its claim could be restructured under the mechanism without its consent. If there is 
such a risk, it will accelerate and foreclose. As will be discussed in Section VII, the approach recommended would be to insulate privileged creditors from the majority restructuring provisions of the SDRM. If this approach is followed, it may not be necessary to suspend these provisions.

149. For the reasons stated above, and in light of the general principles discussed in the outset of the paper, it is not recommended that contractual provisions be automatically suspended upon the activation of the SDRM. Permitting such provisions to operate without suspension would also be consistent with another important principle: early engagement with creditors. For sovereign debtors who are trying to restructure their claims without a default, such a strategy will have the greatest chance of success if the sovereign has been able to make substantial progress in its negotiations with its creditors prior to activation of the SDRM. In these circumstances, the risk that creditors who are being paid will decide to accelerate their claims will be reduced, although such an incentive will still exist in circumstances where, for example, the value of the security is falling.

\section{Other Consequences}

150. Would any other legal consequences flow directly from the activation of the mechanism? Two issues merit particular attention: (i) the valuation of claims for voting and distribution purposes and (ii) the accrual of contractual and penalty interest.

\section{Valuation of claims}

151. In the nonsovereign insolvency context, all claims payable in foreign currency are normally converted into local currency at the exchange rate prevailing on the date of activation. The relative value of claims is therefore fixed from that point forward, both for voting purposes and for purposes of the eventual restructuring agreement (or liquidation, if the restructuring is unsuccessful).

152. Clearly, claims would not be converted into a single currency under the SDRM. However, the question arises as to whether the relative values of currencies should be fixed at the time of activation, for purposes of either-or both-voting and the terms of the restructuring. Taking into account the general principle that interference with contractual claims should be limited to the extent possible, it would seem reasonable that there would be no such fixing of valuations at the time of activation. Rather, once the mechanism has been activated, creditors would continue to bear the risks arising from the fluctuation of the currency of their claims. Of course, some valuation procedure would need to be introduced by the SDDRF to facilitate the voting process; e.g., the value of claims could be fixed no later than 5 days prior to a vote and a single unit of account (e.g., the SDR) would be used to calculate the vote.

153. The valuation procedure will also be relevant with respect to the treatment of privileged claims. Following activation, the value of the assets that form the basis of this privilege may fluctuate. To the extent that — as will be discussed below - the unsecured 
portion of this claim becomes subject to the voting and restructuring provisions of the mechanism, it will be necessary to monitor this fluctuation for purpose of implementing these provisions.

\section{Accrual of interest}

154. Under most insolvency laws, interest stops accruing on creditor claims from the moment of activation. So as to limit any interference with contractual relations, such an approach would not be followed under the SDRM; i.e., interest would continue to accrue after activation. As a matter of practice, however, some of the interest that may have accrued after activation may be written off when the final restructuring agreement is negotiated. This was the approach followed during the restructuring process of the 1980s, where, for intercreditor equity reasons, creditors were unwilling to take into account contractual penalty interest that accrued after a default, preferring to apply a uniform rate of interest.

\section{Creditor Participation: Organization, Voting and Decisions}

155. Once the registration and verification procedure has been completed, creditors will be in a position to vote upon the proposals that have been made by the sovereign debtor. Clearly, the key proposal would be the terms of a restructuring agreement. Ideally, this agreement will have been negotiated prior to activation and the legal feature of the mechanism would only be used to bind the minority of dissenting creditors to its terms. There may be circumstances where less progress has been made prior to activation or where the sovereign may also wish to use another legal feature of the mechanism to facilitate the restructuring process: a decision regarding priority financing. The features of both of these decisions (restructuring decision and priority financing decision), including the specific voting rules that would apply, are discussed below. Finally, as discussed above, it would be appropriate to give creditors holding a requisite percentage of registered claims the right to terminate that SDRM. This issue is discussed in Section IX below.

156. Before turning to issues relating to creditors' decisions, this section will address two issues that are of general applicability to creditor participation in the SDRM: the role of creditors committees and the voting thresholds that would apply to all creditor decisions.

\section{A. Creditor Organization: The Role of Creditors' Committees}

157. As discussed earlier, the SDRM should be designed in a manner that catalyzes early and collaborative dialogue between a debtor and its creditors. To the extent to which the SDRM were able to achieve this objective, it would not only facilitate a rapid restructuring but may also help to enhance emerging market debt as an asset class. Over the last several years, some creditors have complained about the reluctance of debtors to participate in a collaborative dialogue to develop restructuring proposals. In the context of the most recent review of its lending into arrears policy, the Fund also addressed this question and provided further clarity as to what would constitute "good faith" dialogue when determining whether 
to provide financing to a member that is in default on its external debt. In addition to requiring that minimal information be provided to creditors during this period, the new policy also acknowledges the potential role of creditors' committees during the restructuring process. Specifically, in cases in which an organized negotiating framework is warranted by the complexity of the case and by the fact that creditors have been able to form a representative committee on a timely basis, there would be an expectation that the member would enter into good faith negotiations with this committee, though the unique characteristic of each case would need to be considered.

158. What role would creditors' committees play under the SDRM? As contemplated under the above policy, it is anticipated that they could play a key role in the negotiation process in circumstances where the case in question is particularly complex. Not only would it provide the debtor with a single counterpart but also it would play an important role in resolving inter-creditor issues, including issues involving official bilateral creditors. It may also facilitate the restructuring process in other respects. For example, a committee could play a useful role in the verification of claims process: a subcommittee could be established for the specific purpose of determining whether registered claims should be challenged in circumstances where evidence suggests, for example, that the creditor is not independent of the sovereign debtor. As noted in an earlier section, creditor committee approval could also be a vehicle to obtain creditor approval for an order that would enjoin specific enforcement actions.

159. While the SDRM could be designed in a manner that would give creditors' committees the standing to perform these important functions, it would not mandate their formation. Consistent with the Fund's lending into arrears policy, creditors would still need to take the initiative to establish such committees. Moreover, with respect to their role in the negotiating process, these committees would only perform an advisory function- they could not bind the entire creditor body to the terms of a restructuring agreement that they had negotiated with the debtor.

160. If creditors' committees were to perform the above roles under the SDRM, two specific issue would need to be addressed. First, how would a determination be made as to whether a creditors committee was sufficiently representative to enable it to perform the above roles? Second, who would bear the cost associated with operation of these committees?

161. On the first question, that of representation, it would be impossible to identify, ex ante, any numerical criteria. However, based on the experience gained in both the sovereign and nonsovereign context, three criteria would be of particular relevance. First, the committee should include those creditors with the greatest exposure to the sovereign. Second, to the extent possible, it should be sufficiently representative of the diverse financial and economic interests of the creditors whose claims are being restructured. Finally, the size of the committee must be sufficiently small to enable it to operate in an efficient manner. While these criteria could be identified in either the text of the amendment or the associated commentary, their application in specific cases will, no doubt, give rise to disputes. 
Consistent with the approach relied upon in the nonsovereign context, these disputes would be resolved by the dispute resolution body, in this case the SDDRF. It is very likely that, given the diversity of economic interests, a number of committees will be formed. However, in such cases, a steering committee would need to be established to coordinate their activity. In the absence of such a steering committee, none of these individual committees would be considered representative for purposes of the SDRM.

162. With respect to issue of fees, the approach that has been relied upon in the nonsovereign context has been for the debtor to pay for the fees of the legal and financial professionals that are retained by the committee. As was noted in the most recent paper on the Fund's lending into arrears policy, this approach was also followed during the sovereign restructuring that took place during the 1980's, where the fees incurred by the professionals retained by the bank steering committees were paid by the sovereign debtor.

163. Informal contacts with private market participants have highlighted the importance they attach to the payment of fees by the debtor as a means of catalyzing the formation of a representative committee. In the current capital market structure, portfolio managers have stated that they do not have access to substantial resources to devote to workouts.

Accordingly, requiring creditors to cover fees is likely to limit those willing to serve on committees primarily to investors with substantial resources and an appetite for litigation. Moreover, as fees are paid from the resources available for the deal, payment by the debtor ensures that the costs are borne by creditors (in terms of reduced payments that they would receive) in proportion to exposure, thereby promoting intercreditor equity.

164. Accordingly, it is recommended that a representative creditors' committee be given a role under the SDRM to address both debtor-creditor and intercreditor issues. Disputes as to whether a committee is sufficiently representative would be resolved by the SDDRF, taking into consideration the criteria identified above. In light of experience and best practices in this area, it would also be appropriate for the debtor to bear the reasonable costs incurred in the operation of a creditors' committee, and the SDDRF should have the authority to review these fees and reduce them in circumstances where they appear to be excessive.

\section{B. Voting Thresholds}

165. What should be the voting threshold to be relied upon for decisions under the SDRM and how should such thresholds be calculated?

166. On the appropriate level of the voting thresholds, it would seem appropriate to choose a threshold that adequately balances the need to resolve collective action problems, on the one hand, and the need to protect the interests of creditors, on the other hand. In that regard, recent discussions regarding the appropriate voting threshold for voting under collective action clauses revealed a concern by creditors that a 75 percent threshold (which is generally relied upon in sovereign bonds governed by English law) would provide opportunities for the debtor to manipulate the voting process, particularly in circumstances 
where regulated institutions hold a significant percentage of the bond issuance. However, in circumstances where votes are aggregated for voting purposes, this problem will be mitigated, particularly where the claims eligible for restructuring under the SDRM exclude claims governed by domestic law. As noted earlier, while it may be possible for the sovereign to exert enough influence over domestic banks and other domestic entities to affect the vote of a single issuance, it will be more difficult for the sovereign to do so when all foreign law instruments are aggregate for voting purposes. At the same time, aggregation could still give rise to concerns to the extent that there is a perceived risk that fictitious claims could be created.

167. On the method by which the threshold would be calculated, there are two broad options. One approach would be to rely on the quorum rules currently used in sovereign bonds governed by English law. Under this approach, a qualified majority (typically $75 \%$ ) of bondholders attending a duly convened meeting can amend payment terms that become binding on the entire issuance. A duly convened meeting typically requires a quorum of bondholders representing 75 percent of the outstanding principal. If the quorum requirement is not met, a reconvened meeting allows for a lower quorum, typically $25 \%$. The advantage of the quorum approach is that it avoids a situation where a restructuring agreement is frustrated solely because a critical mass of bondholders failed to cast a vote, which may be particularly problematic where the bonds are largely held in the retail sector. As noted by large institutional investors, the disadvantage of the quorum approach is that it could enable a minority of creditors to bind all creditors where only a small percentage of creditors actually attend the meeting. For this reason, creditors have argued that, in the context of collective action clauses, the vote should be calculated on the basis of the outstanding principal. This approach could also be followed under the SDRM.

168. On balance, and subject to the classification rules identified below, it is recommended that the voting threshold be established at $75 \%$ of the total outstanding principal of registered claims.

\section{Priority financing}

169. Activation of the SDRM will not by itself resolve the sovereign's need for new credit. The sovereign could need new credit to continue its governmental and commercial activities, including in order to mitigate domestic fiscal adjustment, to generate the resources to meet external debt service obligations ${ }^{19}$ and to meet the country's needs for goods and services. ${ }^{20}$

${ }^{19}$ For example, this could be in order to finance the purchase and maintenance of inputs that preserve the productive capacity of public enterprises.

${ }^{20}$ For example, the sovereign could borrow externally and on-lend on a revolving basis to firms that need finance to purchase imports in order to produce exports. 
170. The establishment of a framework that would create incentives for private creditors to provide financing during this period could address this need and could usefully supplement financing that would be provided by multilateral organizations during this period. The incentives needed would depend on the creditor in question. For example, to the extent that the sovereign has continued making payments to trade creditors after activation and has provided nonbinding assurances that it would continue to do so throughout the restructuring process, these creditors may be willing to provide new financing. However, other creditors may only be willing to provide new financing if there are legal assurances that this financing will be given priority of payment.

171. What type of legal assurances of priority could be provided under the SDRM that would catalyze new financing? Since the granting of priority of payment to new financing has an impact on existing creditors, any decisions regarding the granting of legal priority would need creditor approval. The question arises as to whether this approval could be granted by a qualified majority. At that time, existing creditors would need to judge whether the anticipated benefit to them would exceed the detriment of such priority.

172. These decisions taken by existing creditors could take a number of different forms, depending on the type of inducement that would be needed in a particular case.

173. For example, a qualified majority of registered creditors could decide that a specific amount of financing would be excluded from the restructuring process. To the extent that any classes are pre-specified in the text of the amendment (see below), creditors holding a qualified majority of registered claims in each class would be required. The exclusion of new credits from the SDRM restructuring as a result of such a vote would be made effective through the requirement that the SDDRF not certify a restructuring agreement that contravened this exclusion unless the creditor that had provided this priority financing agreed to allow its claim to be restructured. Existing creditors could decide to give priority to a specified financing transaction or, alternatively, give this priority to an aggregate amount of credit that meets certain conditions (maturity, interest rate, etc.). ${ }^{21}$

174. A more robust inducement for new financing would involve a decision by creditors to subordinate their claims to those of new creditors. In addition to excluding new financing from the restructuring process, existing creditors could reach an agreement with the priority creditor that would establish intercreditor obligations. The terms of the agreement would provide that, in the event that the priority creditor has not been paid in full by the sovereign, existing creditors would be required to transfer to the priority creditor any amounts that they recover from the sovereign, through judicial proceedings or otherwise. This would, among other things, address the risk of the restructuring failing under the SDRM.

${ }^{21}$ The priority creditor may negotiate a credit that provides for repayment at the time that the restructuring agreement is certified. While the SDDRF would ensure that this credit is not restructured, it would not be expected to ensure that this credit is repaid prior to certification. 
175. As a practical matter, a creditor that wishes to provide new financing with the benefit of this subordination would only be looking for such subordination from creditors that have the demonstrated financial capacity to honor such an intercreditor commitment. For this reason, it is likely that it would identify a list of creditors from which it would seek a subordination agreement. A vote by those identified creditors holding a qualified majority would bind all other creditors on that list. ${ }^{22}$ The legal effect of the subordination agreement would be derived from the SDRM statute and would apply irrespective of whether the proceedings were to culminate in an SDDRF certified restructuring agreement.

176. Although this latter approach would provide the strongest inducement for new financing, it also would represent a significant interference with contractual relations. A minority creditor that did not agree to the priority decisions would not only have to tolerate the exclusion of the priority creditor from the terms of a restructuring, it would also be required to turn over to this creditor any amounts that it may recover from the sovereign in the event that the restructuring fails.

177. On balance, the inclusion of a feature which enables a qualified majority to subordinate all registered creditors is not recommended. However, as a means of inducing new financing, it would be appropriate for the SDRM to provide that a specified amount of financing (or a specified financing transaction) would be excluded from the restructuring if such an exclusion is supported by a qualified majority of eligible creditors.

\section{Restructuring Agreement}

\section{General issues}

178. The features of the decision-making process relating to the final restructuring agreement are clearly the most important component of the SDRM. They are also the most complicated. As discussed in previous papers, the objective is to design a framework that, on the one hand, reduces the holdout problem through the aggregation of creditor claims while, on the other hand, pays regard to the legal seniority of claims and the diversity of creditor interests.

179. Although some of the most difficult issues in this regard relate to creditor classification, it is possible to identify some general issues that would apply to the voting process. Specifically, the following general features are recommended:

180. First, all registered creditors would be asked to vote on the proposed restructuring agreement. Subject to the classification rules discussed below, the agreement would become binding on all registered creditors once the vote has been certified by the SDDRF.

\footnotetext{
${ }^{22}$ The mechanism would probably need to establish some criteria for determining the list; e.g., financial institutions that are in the business of providing credit.
} 
As discussed earlier, as a result of the certification, creditors that failed to register but appeared on the SDRM Restructuring list would also be bound by its terms.

181. Second, it is recommended that a creditor would be deemed to have been unimpaired (and therefore would not be permitted to vote) if the restructuring of the creditors' claim was limited to a reversal of an acceleration of the claim in question (plus payment of any overdue interest), as long as-after giving effect to the restructuring-no other default was continuing. Such a rule, which is used in certain non-sovereign insolvency laws, would effectively enable the debtor to place a creditor in the position it would have been in had there been no insolvency or payment default. As discussed in Section $\mathrm{V}$, this rule would effectively reduce the incentive for a creditor to accelerate its claim solely on the basis of the activation of the SDRM in circumstances where the debtor is otherwise servicing the claims.

182. Finally, when a sovereign debtor proposes a restructuring agreement, it would also be required to provide information as to how it intends to treat claims that are not to be restructured under the SDRM. This will enable holders of registered claims to make a decision regarding the sovereign's proposal with the full knowledge of how other claims are to be treated.

\section{Claims classification}

183. As discussed in a previous paper, a system could be created that would classify creditors into different groups for both voting and distribution purposes. Under such an approach, support by a qualified majority of creditors in each class would be required to approve restructuring terms offered to all classes. While votes would be aggregated across instruments within the same class - thereby greatly reducing the leverage of holdouts - there would be no aggregation of votes across different classes. Finally, while all creditors within the same class would need to receive the same restructuring terms (or menu of terms), treatment of creditors across groups could be different.

184. During the relevant Board discussion, some Directors expressed the concern that, by providing classes with a veto, the above system could prolong the debt restructuring process and suggested that care be taken to ensure that the classification process does not create potential holdout classes. For purposes of addressing these concerns, it is helpful to clarify that there are two very different motivations for classification:

185. The first purpose is to protect the interests of creditors; specifically, to prevent a situation where a minority of creditors with certain interests would be unfairly treated by a qualified majority of creditors with interests that are fundamentally different. In such cases, separate classification would be mandatory (mandatory classes).

186. The second purpose is to facilitate the restructuring process by providing the debtor with the opportunity - but not the obligation - to place creditors with different preferences in different classes in order to permit it to offer different treatment to different groups (optional classes). 


\section{Mandatory Classes}

187. What type of eligible claims would have interests that are sufficiently different that their interests could only be protected if they were placed in a class that is distinct from other creditors? Clearly, the proliferation of such classes would exacerbate the holdout problem, if each class were given a veto. Set forth below is an analysis of the types of differences that may justify separate classification.

188. Official Bilateral Creditors. If official bilateral creditors were to be covered under the SDRM, there is a general recognition (including among those in the private sector) that they would constitute a mandatory class. As a separate class, official bilateral creditors could receive terms that differ from those offered to the private sector so long as both creditor groups accepted them. Thus, it should be possible for the official bilateral creditors - through the Paris Club process - not to give debt reduction (given the budgetary implications for such creditors) in cases where the private sector was prepared to agree to reduce its own debt. However, and as was discussed in an earlier section of the paper, including official bilateral creditors as a mandatory class under the SDRM would require the resolution of a number of difficult issues, including the treatment of non-Paris Club official creditors and the legal authority of representatives of official bilateral creditors to vote on proposals that would be legally binding.

189. Accordingly, if it is decided to include official bilateral claims under the SDRM, it is recommended that they be placed in a mandatory class.

190. Privileged Creditors. Earlier sections of the paper have discussed the role of privileged creditors under the SDRM, recognizing that any interference with their ability to enforce their claims would represent a significant interference with their legal rights. Not surprisingly, this issue also arises in the context of a vote on the restructuring agreement. To the extent that their claims were aggregated with the claims of unsecured creditors for voting purposes, there is a clear danger that, where the unsecured creditors represent the qualified majority, they would vote to effectively strip the value of the privileges from these creditors, which would be unfair.

191. In light of the above, one option would be to establish privileged creditors as a mandatory class. Such an approach, however, will create a number of complications. First, since the interests of privileged creditors could differ from each other (the collateral of one secured creditor may be decreasing in value while that of another is stable), it may be necessary to create subclasses for privileged creditors. Second, to protect the interests of dissenting privileged creditors, it may be necessary to establish some minimum level of treatment. Such a standard could require, for example, that a privileged creditor receive a claim that: (i) when measured in net present value terms, is equal to its original claim and (ii) benefits from some equivalent enforcement privilege. Finally, if this approach were to be followed, other design features of the SDRM may need to be revisited. Most importantly, it may be necessary to impose a stay on enforcement by such creditors immediately upon the activation of the mechanism - otherwise the prospect of an involuntary restructuring of their 
claims would prompt them to exercise their enforcement rights immediately upon activation, even if they are being paid.

192. Under an alternative approach, the claims of a privileged creditor could only be restructured if the creditor in question so agreed; i.e., the existing system would continue to apply to them. This approach would be simpler to apply in many respects, not least because it would not require the establishment of a voting framework for such creditors. Moreover, if such creditors are being paid under the original terms, they are more likely to be willing to voluntarily refrain from accelerating and exercising their enforcement rights if they know that a restructuring cannot be imposed upon them without their consent. However, their consent would not be needed for the overall restructuring agreement to be finalized. As noted earlier, however, to the extent that the value of the privilege is less than the value of the claim, the portion of the claim that does not benefit from the privilege would be subject to restructuring as an unsecured creditor.

193. If the latter approach were followed, the restructuring of privileged claims would take place outside the SDRM and would require their individual approval. To the extent that this may create incentives for the creation of privileges in the future, this incentive can be modulated through the enforcement of negative pledge clauses set forth in loans extended by multilateral development banks. ${ }^{23}$ The Fund could also monitor such financing through surveillance

194. On balance, it is recommended that privileged claims be restructured outside the SDRM; i.e., such restructuring would require the consent of the creditor in question.

195. Unsecured Private Creditors Under the SDRM, are there any circumstances where a sovereign debtor would be required to place general unsecured eligible claims in different classes from each other? Stated differently, could the interests of a particular type of unsecured creditor be so fundamentally different from those of other such creditors that the debtor should be precluded from aggregating their claims for voting and distribution purposes?

196. The principal issue that arises in this regard is whether the different terms of instruments (including different interest rates and maturities) held by these creditors require differential treatment. Is it problematic that a qualified majority of creditors holding instruments with certain terms could vote to approve a restructuring agreement that would be

${ }^{23}$ As an exception to this rule, one could limit the advantage that a litigant would otherwise have if, through enforcement action, it obtained a judicial lien on the sovereign's assets during the period between activation and the restructuring agreement. Such liens would not be treated as privileged claims for voting and distribution purposes and, therefore, could be restructured as an unsecured claim. 
particularly onerous on the holders of claims possessing very different terms? For example, holders of long-term bonds having a qualified majority could vote for a restructuring that would provide, inter alia, for a significant lengthening of maturities of all short-term instruments.

197. To the extent that all of the claims have been accelerated when the restructuring agreement is proposed, the above issue is resolved by the fact that all creditors can be considered to have claims that are of the same maturity; i.e., they are all due and payable. This is the approach that is followed in the nonsovereign context. Moreover, the secondary market prices of sovereign debt also suggest that, once there is a default, investors do not distinguish between claims on the basis of the original maturity. However, the situation could be more problematic in cases where the sovereign has managed to avoid a default - and therefore acceleration - prior to making a restructuring offer. Offering unsecured creditors the same terms would presumably only be acceptable if the risk of default were high enough that creditors were willing to treat all of their claims as having been accelerated.

198. Interestingly, this issue also arises in the nonsovereign context, where a corporate debtor and its creditors agree upon a restructuring proposal before commencement of insolvency proceedings and in circumstances where the debtor continues to service it obligations. Under these pre-negotiated or "pre-packaged" arrangements, proceedings are commenced solely for the purpose of making this agreement binding on the entire creditor body. When these plans are negotiated, unsecured creditors with claims of different maturities are generally willing to be given the same treatment under the restructuring agreement. They are willing to do so because they believe that failure to agree to a viable restructuring plan will result in a general default and insolvency, where they will fare less well.

199. On balance, it is proposed that there be no mandatory classification among unsecured creditors. The claims of all unsecured creditors would be deemed to be due and payable for voting and distribution purposes. Accordingly, a sovereign would have the right to place all unsecured creditors in the same class for voting purposes as long as it offered all of the creditors the same terms or the same menu of terms. As with the nonsovereign model, such an approach is particularly appropriate if the SDRM is reserved for unsustainable cases; i.e., where, absent a restructuring, it is likely that there will be a general default on all registered claims.

200. If the proposed approach were followed with respect to all of the above groups of creditors, there would be only two mandatory classes: (i) official bilateral creditors and (ii) all other eligible claims that do not benefit from a privilege.

\section{Optional Classes}

201. Even though the sovereign would have the right to place all unsecured private creditors in the same class, there may be circumstances where it may find that it 
advantageous to place them in different classes so as to provide them with different treatment. In what circumstances could this arise?

202. There may be circumstances where the sovereign may wish to offer a particular set of terms to certain creditors that materially differ from those offered to others and would want the assurance that the agreement will become final only if these terms are acceptable to the creditors that are offered them. ${ }^{24}$

203. For example, a sovereign may need to restructure claims that were originally interbank claims or trade credit but have become claims on the sovereign because of a guarantee that has been called. In these cases, the sovereign may need to provide these creditors with terms that are preferable to those offered to bondholders, because of the need to resume normal inter-bank and trade financing after the crisis subsides. Since these preferential terms could only be offered to these trade and bank creditors, these creditors would be placed in a separate class from bondholders. (If the claims of bondholders and bank creditors were placed in a single class, a menu of options would need to be offered to all creditors within the class on a uniform basis, and could not discriminate among types of investors.) The restructuring would only become effective if a qualified majority in each class supported the restructuring. For their part, bondholders may be willing to accept being treated less favorably because of the recognized need to resume inter-bank and trade credit. Another possible situation is where the sovereign is of the view that it can offer terms to domestic banks holding external claims that are less favorable than those offered to external creditors holding the same claims. Such banks may be willing to accept these claims in exchange for some degree of regulatory forbearance.

204. As can be seen, a system of optional classification would constitute a potential tool for the sovereign - not an obstacle to a restructuring. Unlike a mandatory class, it would be for the sovereign to determine whether such a class is created and it would do so when it believed that it would facilitate a sustainable restructuring.

205. Would a system of optional classification need to provide safeguards to protect the interests of creditors? As noted above, creditors within the same class would have to be offered the same terms (or menu of terms). To the extent that a group of creditors objects to being placed in a separate class and being given different treatment, it would simply exercise its veto to reject the proposal, in which case the sovereign would need either to make the offer more attractive or place these creditors in the general class.

206. Notwithstanding these safeguards, however, additional protection may be needed to protect minority creditors from "gerrymandering"; i.e., from being placed in totally artificial

${ }^{24}$ Although a menu of options within the same class provides some flexibility, it is limited by the fact that, in terms of their net present value, the options would need to be equivalent in order for their to be any predictability as to the financial implications of the restructuring. 
classes. One could envisage, for example, a situation in which some creditors are arbitrarily assigned to a creditor class in which the qualified majority of exposure is held by creditors with very different economic interests, while other similarly situated creditors are assigned to another creditor class. ${ }^{25}$

207. Informal contacts with market participants indicate a recognition that the ability to establish optional classes has worked well in the nonsovereign context and could be a powerful tool in the sovereign context. These contacts stressed, however, the importance of safeguards against gerrymandering.

208. Accordingly, it would be reasonable to give the sovereign the ability to create optional classes. However, this ability should be limited by a requirement that such classes may not be created in a manner that results in unjustified discrimination of creditor groups, taking into consideration their varying economic interests. To the extent that the debtor proposes a class structure that creditors believe violate this rule, such a dispute would be resolved by the SDDRF. However, and to reiterate a previous point, as long as the creditors in question are unsecured private creditors, the debtor would have the right to place them all in a single class, notwithstanding any differences in their economic interests.

\section{Multiple Debtors}

209. Depending on the type of claims are included on the SDRM Restructuring list, there may be more than one debtor that is proposing an agreement. As noted in Section IV above, in cases where the government includes the indebtedness of other entities (e.g., the central bank or a subnational government) there could be separate restructuring agreements proposed for each of these entities and the effectiveness of these agreements would depend on support by a qualified majority of the creditors of that entity. Of course, in some circumstances the creditors may agree to a proposal made by the sovereign that involves the central government (or the central bank) assuming all of these obligations.

210. In cases, however, where the indebtedness of different entities is not consolidated, the question arises as to whether a restructuring agreement with respect to one of the debtors can go into effect even though creditors have not approved a proposal made by another debtor. On the one hand, it could be argued that a return to sustainability may necessitate the establishment of rule whereby the restructuring of the debt of one entity will only go into effect when the debt of all other entities is restructured. One the other hand, such a rule would give the debtors of one of the entities undue leverage over the process. For example, creditors of a public utility that has been brought into the SDRM process (because it is not

\footnotetext{
${ }^{25}$ For example, the debtor would be precluded from creating two different classes of unsecured creditors where certain inter-bank creditors are placed in their own class and given short-term instruments while other inter-bank creditors are placed in another class with bondholders and are given long-term instruments.
} 
subject to the domestic insolvency framework) could hold up a restructuring of the debt of the central government.

211. For the above reason, it is recommended that the SDRM allow for a restructuring agreement applicable to one debtor to become effective even though an agreement has not been reached with another debtor. Of course, as with claims that are being restructured outside the SDRM, creditors may choose not to approve a proposal by their own debtor until they are satisfied with the terms that have been accepted by creditors of another debtor.

\section{Performance Under the Restructuring Agreement}

212. Once the SDDRF has certified that registered creditors representing a qualified majority of registered claims have accepted the restructuring agreement, the SDRM procedure would terminate. In the event that the debtor defaults on its obligation under the agreement shortly after a restructuring agreement is reached, such a default would not automatically reinstate the original obligations or trigger a reactivation of the SDRM. Creditors would be free, however, to include in the restructuring agreement provisions that effectively reinstate the value of the original claim in the event of a default.

\section{SANCTIONS}

213. The effectiveness and credibility of the SDRM will be enhanced if there are sanctions that would create disincentives for abuse. At the same time, establishing effective penalties must take into consideration the general principles that the formal role of the Fund under the SDRM should be limited.

214. When considering the nature and role of sanctions under the SDRM, it is helpful to distinguish between two different types of abuse:

215. The first type of abuse involves the provision of false information. For example, there may be circumstances where creditors provide false information in the context of the claims registration and verification process. Presumably, creditors that engage in these activities would be subject to criminal or civil liability in accordance with their own domestic laws.

216. Establishing credible sanctions for sovereign debtors in these circumstances is more complicated. One approach would be to provide that such actions by the sovereign would constitute a breach of its obligations under the Articles of Agreement. These actions would include providing materially incorrect information to the SDDRF regarding its debt situation and providing false certification regarding its relationship with creditors that participate in the voting process.

217. If such an approach were to be adopted, it may be preferable for the Executive Board to be given the final authority to determine whether a member has breached its obligations and what sanctions should apply. To ensure uniformity of treatment and predictability, the Board could adopt policies outlining steps it would be expected to take when the SDDRF 
reports that information is inaccurate. Policies could be established that would provide, for example, that all purchases under an arrangement would be automatically suspended upon a determination of a breach of this obligation. While these sanctions would be credible, they would have the disadvantage of enhancing the role of the Fund in the process. ${ }^{26}$

218. The second type of abuse would take the form of general noncooperation or inappropriate use of the framework, as a result of actions taken by the debtor or its creditors. For example, the sovereign may refuse to negotiate with a creditors' committee even though there is no dispute as to whether such a committee is adequately representative. More generally, it may refuse to provide information to creditors or otherwise engage in a collaborative dialogue. In such circumstances, it would not be necessary to establish specific penalties in the text of the SDRM itself. Creditors could merely refuse to support a restructuring proposal or a proposal relating to priority financing. Moreover, where litigation is initiated, the creditors' committee would not support any request for injunctive relief by the SDDRF, to the extent that this feature is included. Finally, as is described below, the creditors would have the right to terminate the SDRM, which may be particularly relevant in circumstances where they form the view that its activation was not justified.

219. With respect to the SDDRF, it would have the general power to terminate the SDRM in circumstances where it has reached the conclusion that there is no reasonable prospect of progress in the restructuring process, irrespective of where the responsibility for failure may lie. Similarly, if the debtor terminates the SDRM procedure for reasons which the SDDRF believes are unjustified, the SDDRF could adopt rules that would preclude the debt from reactivating the SDRM within a particular period, say 6 months.

220. Of course, the Fund would also be able to use its financial powers to address noncooperation, and the exercise of these powers would not need to be formally recognized under the SDRM. In circumstances where a sovereign refused to engage in a "good faith" dialogue with its creditors during the restructuring process, the Fund could withhold financing, consistent with its existing lending into arrears policy. At the same time, however, where negotiations become stalled because creditors are requesting terms that are inconsistent with the adjustment and financing parameters established under the Fundsupported program, the Fund could decide to continue to support members, notwithstanding the lack of progress in negotiations.

\section{It is recommended that the provision of false information by the sovereign during the restructuring process constitute a breach of the member's obligations under the}

\footnotetext{
${ }^{26}$ Creditors could, of course, also design their own penalties. For example, the terms of the eventual restructuring agreement could provide that, in the event that evidence comes to light that the information provided to the SDDRF and creditors was materially inaccurate, their original claims could be reinstated. Disputes relating to the implementation of this clause (or other clauses in the restructuring agreement) would be subject to the jurisdiction of the national or arbitral court designated in the agreement.
} 
Articles of Agreement. With respect to sanctions for noncooperation or inappropriate use of the mechanism, it is recommended that the Fund would rely on its existing financial policies, including its policies on the use of its resources.

\section{TERMINATION}

222. The SDRM procedure would terminate upon the certification of the restructuring agreement by the SDDRF. In addition, and consistent with the principle of sovereignty, the sovereign debtor could terminate the operation of the mechanism at any time, although sanctions would need to be in place to ensure that this right is not exercised in a manner that results in an abuse of the mechanism.

223. It is recommended that the SDDRF have the power to terminate the operation of the mechanism on the basis of its assessment that continuation does not serve a constructive purpose because of compelling evidence of a breakdown in relations between the sovereign debtor and its creditors.

224. It is also recommended that the creditors have the right to terminate the procedure at the expiration of the verification period. Creditors could be asked to vote upon a motion of early termination if such a vote is requested by a minimum percentage of creditors, say ten percent of outstanding principal.

225. A question arises as to what the voting threshold should be for such an early termination decision. One approach would be to apply the general threshold that is applicable to other decisions; i.e., 75 percent of the outstanding principal of registered claims. Alternatively, the decision could be taken by an affirmative vote of a percentage of claims that would represent a blocking minority to any restructuring agreement; e.g., 40 percent of outstanding principal.

226. Once the SDRM procedure is terminated, the jurisdiction of the SDDRF over the restructuring process would also terminate. Thus, even though a restructuring agreement may have been certified by the SDDRF, the SDDRF would have no jurisdiction over its interpretation. Rather, the interpretation and enforcement of the agreement would be the responsibility of the national or arbitral tribunal that has been given jurisdiction under the terms of the agreement, as discussed below.

\section{The Sovereign Debt Dispute Resolution Forum (SDDRF)}

227. An essential feature of the SDRM would be the establishment, through an amendment of the Articles of Agreement, of a dispute resolution forum, the proposed Sovereign Debt Dispute Resolution Forum (SDDRF). The SDDRF would be established on the basis of the following general considerations: 
- The SDDRF would have limited powers. It would have powers to ensure the proper conduct of the proceedings, resolve disputes, and certify that a restructuring agreement binding the debtor and the creditors has been approved by the required majority of creditors in accordance with the required procedures. Depending on the design of the mechanism, it may also have the power to enjoin specific enforcement actions in exceptional circumstances upon the request of the debtor and approval of creditors. It would also be allowed to adopt rules of procedure for the performance of its functions.

- Recourse to the SDDRF would only be available upon the activation of the SDRM by a debtor. Absent the activation of the SDRM, the SDDRF would not be available for the resolution of disputes. Upon activation by a debtor, the SDDRF would be available only for the resolution of disputes involving claims against the particular debtor that has activated the SDRM.

- The SDDRF would have exclusive jurisdiction over the conduct of the SDRM process and disputes arising from that process. However, there will be other ancillary issues stemming from the SDRM process over which national courts will have jurisdiction.

- The SDDRF would be independent. Although it would be an organ of the Fund, the SDDRF would be established in such a manner that it would operate-and would be perceived to operate - independently of the Fund's Executive Board, Board of Governors, management and staff, and any other body or persons. In addition, due regard would be paid to the principles of competence, diversity and impartiality in the selection of SDDRF members.

\section{- The SDDRF would be accountable and transparent with regard to its operations.}

228. The possible composition and powers of the SDDRF were discussed in a previous paper. This section expands that discussion and addresses additional issues regarding the organization and accountability of the SDDRF. In doing so, it discuses the relevant features of other dispute resolution procedures that have been established by international treaty.

229. To enhance the perception of the SDDRF's independence from the Fund, the office of the SDDRF could be located in a city other than Washington, D.C.

\section{A. Establishment of the SDDRF}

230. Staff's proposals on the method by which the SDDRF would be established are informed by the nature of the functions envisaged for the SDDRF. These proposals also take into account existing dispute resolution bodies of other international organizations.

231. There are, broadly, two types of dispute resolution fora that staff has surveyed with regard to other international organizations. The first type consists of adjudication fora that are 
comprised of permanent sitting judges, such as the UN's International Court of Justice (ICJ) or the European Court of Justice (ECJ). The second type relies on the establishment of ad hoc panels of judges or arbitrators that are only convened in the context of a dispute but which are drawn from a permanent pool of judges or arbitrators that have been selected in advance. Examples of this second approach include the International Center for the Settlement of Investment Disputes (ICSID), the World Trade Organization (WTO) and the North American Free Trade Agreement (NAFTA).

232. The approach proposed by the staff with respect to the establishment of the SDDRF and the selection of its members would be similar to the approach relied upon by ICSID, the WTO and NAFTA; ie. while a permanent pool of judges would be selected and appointed in advance, an adjudication panel would only be created when a crisis arises. Until that time, the judges would continue to work in their own countries and in their other capacities. There are a number of advantages to this approach:

- Delays in the selection of a panel would be avoided. The establishment of a permanent pool enables potential panel members to be identified prior to the crisis;

- There would be consistency in the interpretation of rules, leading to predictability of results; and

- Each new case would benefit from the accumulation of experience acquired in earlier cases.

\section{B. Appointments to the SDDRF}

233. As discussed in earlier papers, the process for the appointment of SDDRF "members" (i.e., the individuals who would form the pool from which a panel would be selected once a crisis arises) would be guided by four basic principles: independence, competence, diversity and impartiality. Drawing on the practice of international organization, the proposed process described below would consist of the following steps: (i) designation of a selection panel; (ii) identification of potential candidates and adoption of a list of qualified candidates by the selection panel; (iii) submission to the Board of Governors of the list of candidates for an "up or down" approval; and (iv) formal appointment by the Managing Director of the approved candidates.

\section{Designation of Selection Panel}

234. There are at least two possible options for designating the "selection panel"; i.e. the panel that would select the permanent pool of judges. Under the first option, an independent and qualified panel of 7-11 judges from the highest courts of a representative group of member countries of the Fund could be appointed to select the candidates for appointment to the SDDRF. The Executive Board could choose 7-11 representative member countries and ask the authorities of those countries to each forward the name of one judge. The forwarded names would constitute the selection panel. 
235. Under the second option, which is the one recommended by the staff, the Managing Director would appoint 7-11 independent and qualified persons to the selection panel on the advice of professional associations of insolvency and debt restructuring experts (such as the International Federation of Insolvency Professionals (INSOL International)), and public or private international organizations that have developed an expertise in insolvency and debt restructuring matters (such as the United Nations Commission on International Trade Law (UNCITRAL)). Members of the selection panel would be active or former judges and practitioners in the field of insolvency and debt restructuring. ${ }^{27}$

236. Appointment by the Managing Director would be perceived as being less political than appointment by the Executive Board and would avoid the distortions that could result from weighted voting. Moreover, by including the views of respected outside parties, the second option could be perceived as enhancing the independence of the process from the other organs of the Fund. Legal and judicial experts that have been consulted regarding the design of the SDDRF are also of the view that this approach would greatly enhance the perception of independence. ${ }^{28}$

\section{Identification of Potential Candidates by the Selection Panel}

237. Once appointed, it is recommended that the selection panel be charged with identifying 12-16 candidates that would constitute the pool from which judges would be impaneled when a crisis arises. The candidates selected would include a President and Alternate President of the SDDRF.

238. It is recommended that the panel be able to receive nominations from Fund members and from any other persons or organizations (including self-nominations). In addition, the panel would be authorized to identify, on its own initiative, candidates for its consideration. Based on consultation with legal and judicial experts, an open nomination system, as described above, would be preferable to one where the nominations are limited to those received from members for at least two reasons. First, it would allow for candidates to be selected from a broader pool of talent and experience. Second, it would reduce the amount of influence that political forces would play in the selection process.

\footnotetext{
${ }^{27}$ A "former" judge or practitioner would not necessarily mean one that is retired. For example, one could imagine a former insolvency judge who has left the judiciary to pursue other interests, but maintains his or her expertise in insolvency matters.

28 The rules for the panel's operations, including rules on the selection of its chairman and on its decision-making process, would have to be addressed. Some of these rules may have to be specified in the amendment, but others could be established by the panel itself.
} 
239. To assure adequate representation of the views of creditors and other interested parties, it is recommended that the selection panel also be required to take into account the advice of independent, international, professional associations that are expert in insolvency and debt restructuring, and the views of private creditors' associations, member countries, Executive Directors and any other interested parties. ${ }^{29}$ In making its assessment of the candidates and producing its list of 12-16, the panel would be required to adhere to selection criteria that would be specified in the amendment to the Articles. The criteria would encompass the following aspects:

- judicial experience in insolvency or related matters and debt restructuring; ${ }^{30}$

- $\quad$ specified requirements on competence and impartiality; and

- diversity of legal backgrounds and a limit of not more than two candidates of the same nationality.

240. Competence and impartiality would be given priority over all of the other criteria. Moreover, when assessing competence, the selection panel would need to take into consideration whether the nominees had expertise in the laws that govern international sovereign debt generally. The amendment to the Articles could require that the panel's list of 12-16 candidates, and its choice of President and Alternate President of the SDDRF, be adopted by the selection panel by consensus. The amendment to the Articles could empower the Board of Governors to enlarge the number of nominees that can be designated by the selection panel.

\section{Approval by the Board of Governors}

241. At the end of its identification process, the selection panel would forward to the Board of Governors, through the Executive Board, a list of 12-16 names for approval. If it so wishes, the Executive Board could make recommendations to the Board of Governors, but the Executive Board would have no veto powers on the list selected by the committee.

\footnotetext{
${ }^{29}$ International professional associations that could be consulted include the International Federation of Insolvency Professionals (INSOL International), the International Bar Association's Committee J, and the International Insolvency Institute (III). In addition to direct consultation between the selection panel and these and other groups, a website could also be established for comments on the list of nominees by any person who would like to comment.

${ }^{30}$ Private sector creditors consulted by the staff have suggested that SDDRF members should be judges that are highly qualified in insolvency and debt restructuring rather than academics or practitioners. These creditors feel that only trained judges would have the expertise to deal with the complex disputes that would inevitably arise. However, they are also concerned that the pool of such judges that may be willing and able to serve is probably quite small. Thus, they have expressed support for opening up the positions to retired or other former insolvency judges.
} 
242. After receiving the list of candidates, the Board of Governors would vote on it on an up or down basis (i.e., the Board of Governors would not have the ability to select or exclude individual nominees from the list). If the list is rejected, the process would have to start all over again. The reason for recommending an up or down vote is to avoid the perceived distortions that may arise in the selection process from weighted voting if the Board of Governors were able to pick and choose from the list.

\section{Formal Appointment of SDDRF Members}

243. Based on the above recommended appointment process, the Managing Director would be responsible for making the formal appointment of each member of the SDDRF. SDDRF members could serve for terms of, say, six years each, with one-half of the members subject to renewal every three years. The selection panel would be reconstituted every three years to recommend new candidates as well as to endorse existing members for reappointment. To avoid having to reconstitute the panel every time there is a vacancy, the amendment to the Articles could provide that the SDDRF could operate with less than the full complement of members, but no less than a specified number. ${ }^{31}$

244. It is important to emphasize that, except for the President of the SDDRF (who would be selected in accordance with the procedure set forth below), other SDDRF members would continue to work in their other capacities until they are impaneled.

\section{Organization of the SDDRF}

245. This section addresses the organizational needs of the SDDRF, including the selection of a president, the adoption of rules of procedure, a process for impaneling members for particular cases, the establishment of a secretariat, funding of the SDDRF, employment benefits, and immunities and privileges.

\section{Selection of the President}

246. The SDDRF would need a presiding member to direct and supervise the work of the forum and an Alternate President to exercise the duties and powers of the President when the President is unable to do so. The amendment to the Articles could establish the duties and powers of the President. Alternatively, the Board of Governors could be given the authority to establish by-laws for this purpose. Unlike other members of the SDDRF, the President would work on a full-time basis. As noted in above, the amendment to the Articles could require that the selection panel identify the first President and the first Alternate President. Future presidents and alternate presidents could be selected by a procedure

${ }^{31}$ The amendment to the Articles would also need to establish the procedures and standards for dismissal in case of improper behavior by an SDDRF member impaneled for a particular case. One option could be that SDDRF members would be subject to dismissal only upon the unanimous decision of all other SDDRF members. 
specified in the amendment. Such a procedure could be that members of the SDDRF would elect a presiding member from among themselves. ${ }^{32}$

\section{Rules of Procedure}

247. The SDDRF would require rules of procedure in order to facilitate the exercise of its powers. ${ }^{33}$ There are at least two options by which such rules could be established:

- The amendment to the Articles could grant rule-making authority to the SDDRF, providing only the broad contours of such rule-making authority, including the manner by which such rules would be made. A rules drafting committee of, say, five SDDRF members could be constituted by the President. The draft rules would then have to be ratified by the entire SDDRF in accordance with a procedure that could be prescribed in the amendment. ${ }^{34}$

- Some of the rules of procedure could be drafted at the outset as part of the amendment to the Articles of Agreement. The SDDRF would be given the power to supplement the rules as necessary but within the existing framework.

\section{It would seem reasonable to draft a number of the basic rules of procedure at the time of the amendment of the Articles. These rules could be supplemented by the SDDRF}

\footnotetext{
${ }^{32}$ This is a common procedure in other international organizations (See ICJ Statute, Art. 21(1); WTO Appellate Body Working Procedures, Article 5(1)).

${ }^{33}$ The rules of procedure would address issues such as communications with the SDDRF; filing, registration, notifications, administration of voting; dispute resolution, including on evidentiary standards, written and oral proceedings, verification of claims, integrity of the voting process, and creditor classification; the SDDRF's powers of interpretation (its own decisions, the SDRM Amendment, including the SDDRF's jurisdictional powers), procedural rule-making, and the appeals process; conflicts of laws and recognition of rulings of other courts; the internal workings of the SDDRF, including its relationship with its secretariat, internal discipline, impaneling, and conflicts of interest.

${ }^{34}$ The grant of such rule-making authority is common in the dispute resolution fora of other international organizations. The International Court of Justice, for example, has been granted the authority to establish its rules of procedure and rules for its internal workings. Article 30(1) of the ICJ Statute provides: "The Court shall frame rules for carrying out its functions. In particular, it shall lay down rules of procedure." In the Fund, members of the Administrative Tribunal, by majority vote, establish the rules of procedure for the Tribunal (Statute of the Administrative Tribunal, Article X.2). For certain other fora, the grant of rule-making authority is more limited. The WTO Appellate Body, for example, has authority to establish its rules of procedure, but only if this is done in consultation with the Chairman of the Dispute Settlement Body (a body composed of member states of the WTO that oversees the WTO's dispute settlement system) and the Director-General of the WTO Secretariat (See Article 17(9) of the WTO Understanding).
} 
over time since it would be very difficult to foresee all of the necessary rules upfront. Staff, thus, recommends the second option.

\section{Impaneling}

249. A question arises as to how an SDDRF panel would be selected from the permanent pool of SDDRF members once a crisis arises. One option would be to follow the arbitration approach relied upon by organizations such as ICSID, where the parties select the panel members from the permanent pool. However, such an approach would not be suited to SDRM dispute resolution process for a number of reasons. Most generally, existing arbitral models are based on the assumption that all parties would agree to have their claims adjudicated by the arbitral body. Clearly, such an approach could not be relied upon in circumstances where the very source of the problem relates to problems of collective action. Although one could design a new type of arbitral framework that would overcome this collective action problem (e.g., where a qualified majority could select an arbitrator that would have jurisdiction over all creditors), the SDDRF would not be able to operate as an arbitral tribunal for the following reasons:

- In arbitration cases, the parties are known; therefore, both sides can participate in the selection of the panel of arbitrators. Under the SDRM, the creditors will first have to have their claims verified in order to be recognized for participation in decisionmaking. Thus, the selection of a panel would have to follow, not precede, the verification process. But then who would resolve disputes arising from verification if there was no panel already in place?

- Additionally, in arbitration cases, there are only two sides to a dispute, with each side having the right to select or approve "its" arbitrator. Under the SDRM, there may be many creditors with conflicting interests, who may each want to appoint their own arbitrator. This could be unmanageable and could distort the balance of power between the debtor- and creditor-selected arbitrators.

250. In light of the above, and based on consultation with judicial and legal experts, the staff recommends that four members of the SDDRF be impaneled by the President of the SDDRF in a manner that ensures impartiality. ${ }^{35}$ The President would be required to take due care to ensure that members with conflicts of interest in specific cases are not permitted to serve in those cases. One approach, which is utilized by the judiciary in some member countries, would involve the President developing a secret list in consultation with the panel members, where a number of panel members would be "on call" for a particular quarter of the calendar year, subject to general rules regarding conflicts of interest.

\footnotetext{
${ }^{35}$ Other members not impaneled would continue to work in their other capacities. As described above in the section on Appointments to the SDDRF, creditors and debtors would not be able to choose members for a panel.
} 
251. One of the four members impaneled would be appointed by the President as the supervisory judge for the case. The supervisory judge would be responsible for overseeing the proceedings before the SDDRF, and would make the initial determinations required of the SDDRF. The other three impaneled members would constitute an appeals panel. ${ }^{36}$ On the basis of consultation with legal and judicial experts, staff is of the view that such an arrangement would facilitate dispute resolution and a faster conclusion of the SDRM process by providing immediate appellate review. There would be no further appeals permitted. The rules regarding the appeals process, including the permissible grounds for appeal and the standards of review, would be established in the rules of procedure. ${ }^{37}$ The standards of review could be established to give broad scope for appeals to go forward.

\section{Secretariat}

252. The amendment would outline the duties of the secretariat and establish that it would be independent of the other organs of the Fund and would owe its duty of allegiance to the SDDRF. The secretariat would perform functions similar to those performed by the secretariats of dispute resolution fora in other international organizations. Typical functions that would be performed by the secretariat include: registry; acting as the official channel of communication to the SDDRF; preparing the minutes of SDDRF meetings and maintaining its archives; publishing certifications and decisions of the SDDRF and other publishable materials; providing translation and interpretation services; and overseeing the administration of the SDDRF, including financial management. The secretariat would consist of a small permanent staff of two or three. As needed, additional staff and consultants could be hired on a temporary basis, e.g., to provide expert advice on technical issues.

253. Two options are suggested with regard to the recruitment and appointment of the secretariat: (i) by the Managing Director, in consultation with the President of the $S D D R F$; and (ii) by the President of the SDDRF, in consultation with the Managing Director. ${ }^{38}$ Staff recommends the second option in order to minimize concerns regarding independence of the SDDRF from the Fund.

\footnotetext{
${ }^{36}$ Similar systems are common in a number of civil law countries in Europe (The Netherlands, France, for example). The appellate process would not preclude the SDDRF from establishing rules for the review by a supervisory judge of his or her decisions before the appeals process is engaged.

${ }^{37}$ In most dispute resolution fora in international organizations, there is no recourse to an appeals process. Prominent exceptions include the WTO Appellate Body and the European Court of Justice (consisting of the Court of Justice and the Court of First instance). The Court of First Instance has jurisdiction to hear and determine at first instance certain classes of action subject to an appeal to the Court of Justice on points of law (TEEC, Art. 225.1).

${ }^{38}$ The Fund has two recent precedents for establishing the secretariat/staffing of an independent organ of the Fund. The secretariat of the Fund's Administrative Tribunal performs similar functions to those envisaged for the secretariat of the SDDRF (Rules of Procedure, Rule IV). The administrative
}

(continued) 


\section{Budgetary Issues $^{39}$}

254. Under current procedures, the Managing Director is responsible for implementing the budget following approval by the Executive Board of the principal expenditure heads. This process could raise questions regarding the independence of the SDDRF from the Fund. Possible options for funding could be:

- The procedure used for the Administrative Tribunal. ${ }^{40}$

- The procedure used for the Independent Evaluation Office. ${ }^{41}$

arrangements necessary for the Administrative Tribunal, including designation of personnel, are made by the Managing Director of the Fund, although the personnel assigned to the Tribunal are independent from the Fund and work under the authority of the President of the Tribunal (Statute of Administrative Tribunal, Article IX and Commentary to Report of the Executive Board to the Board of Governors on the Establishment of an Administrative Tribunal for the IMF.) In contrast, the Director of the Independent Evaluation Office (IEO) is solely responsible for the selection of IEO personnel (including external consultants) on terms and conditions set by the Executive Board with a view to ensuring that IEO is staffed with independent and highly qualified personnel. When the office is fully staffed, a majority of its personnel will come from outside the IMF. In addition, IEO staff report exclusively to the Director of IEO, not to IMF management. (See Terms of Reference of IEO).

The ICJ chooses its Registrar and Deputy Registrar (ICJ Rules of Court, Articles 22 and 23). Staff of the registry are appointed by the Court on the proposal of the Registrar. Certain staff appointments may require the approval of the President of the ICJ (ICJ Rules of Court, Article 25). The Registrar and Deputy Registrar can be dismissed only by Court (ICJ Rules of Court, Article 29).

${ }^{39}$ The administrative expenses of international dispute resolution bodies are typically borne by the international organization under whose auspices they are established. However, parties to a dispute bear their own costs. Expenses of the ICJ are borne by the UN "in such a manner as shall be decided by the General Assembly." (Article 33 of ICJ Statute.) WTO panelists expenses and the expenses of the Appellate Body are met from the WTO budget (WTO Understanding, Articles 8(11) and 17(8)), in accordance with criteria adopted by the General Council of the WTO, on the recommendation of the committee on budget, finance and administration. In contrast, the NAFTA Commission decides on the level of remuneration and expenses to be paid to Chapter 20 panelists and others, but the actual payments are made by the parties to the dispute (Chapter 20, Article $2002.2 \mathrm{~b}$ ) ii and Annex 2002.2(1) and (2)). ICSID operations are financed from the charges for use of its facilities and other receipts. Any shortfalls are paid for by the contracting states. (ICSID Convention, Article 17).

${ }^{40}$ Under the normal budgetary procedures of the Fund, the expenses of the Fund's Administrative Tribunal are borne by the Fund (Statute of Administrative Tribunal, Article IX.3). The parties, with certain exceptions (Statute of Administrative Tribunal, Article XIV.4 and XV.1), are responsible for their own expenses.

${ }^{41}$ The Director of IEO, in consultation with Executive Directors, prepares a budget proposal for IEO for consideration and approval by the Executive Board. Its preparation is independent of the budgetary process over which management and the Office of Budget and Planning have authority, but

(continued) 
- The selection panel could play the additional role of advising the Managing Director on an appropriate budget for the SDDRF for the first year. In subsequent years, the Managing Director would consult with the SDDRF, taking into account what happens at other international dispute resolution fora. Further, each time the selection panel is reconstituted as described above in the section on Formal Appointments to the SDDRF, it could also advise the Managing Director on budget issues.

255. The staff recommends the third option since the views of respected outside parties would enhance confidence in the independence of the SDDRF from the Fund.

\section{Employment Benefits}

256. Other than the President, members of the SDDRF would not be full-time employees and would be paid only when they were working. The President could be paid a special allowance for the extra duties required of the office.

\section{Immunities and Privileges}

257. For purposes of the immunities and privileges of the Fund, the amendment to the Articles could provide that SDDRF members would be treated as "officers of the Fund" and staff of the secretariat would be treated as "employees of the Fund" under Article IX. ${ }^{42}$

\section{Powers of the SDDRF}

258. The SDDRF would have powers regarding the conduct of the proceedings and dispute resolution. With regard to dispute resolution, its powers would be essentially reactive; the SDDRF would not, on its own initiative, consider issues that have not been raised by the parties. The SDDRF would be able to request additional evidence from the parties, but would have no subpoena powers. As discussed in Section VI above, failure by a party to provide requested evidence could lead to the dismissal of the parties claim or request to the SDDRF.

its implementation is subject to the Fund's budgeting and expenditure control procedures. IEO's budget is appended to that of the Executive Board within the Fund's Administrative Budget (IEO Terms of Reference).

${ }^{42}$ Members of the Fund's Administrative Tribunal are considered as "officers of the Fund" for purposes of the immunities and privileges in Article IX, Section 8 of the Articles of Agreement (Statute, Article VIII). Article 19 of the ICJ Statute provides diplomatic privileges and immunities to members of the Administrative Tribunal of the ICJ. ICSID property, assets, officers, employees, and panelists have similar immunities and privileges to those in the Fund's Article IX (ICSID Convention, Articles 19-23). ICSID Convention, Article 22 extends immunities, in the course of travel to and from proceedings and during stay at proceedings, to parties, agents, counsel, advocates, witnesses and experts. 
259. The SDDRF would have no authority to challenge decisions of the Executive Board, including with regard to the adequacy of a member's policies or the sustainability of the member's debt for purposes of Fund financial assistance. As discussed above, the SDDRF could be granted limited procedural rule-making authority to facilitate the exercise of its powers.

\section{Administrative Functions}

260. As described in Section VI above, this would involve purely administrative functions such as notification to creditors, registration of claims, and administration of the voting process. ${ }^{43}$

\section{Dispute Resolution}

261. The SDDRF would be charged with resolving disputes arising between the debtor and creditors on the one hand, and amongst creditors on the other hand. As described in Section VI above, most disputes are likely to arise during the claims verification and voting process. Specifically, the debtor or creditors may challenge the value or validity of a claim submitted. Moreover, in the context of the voting process, disputes may arise as to whether a vote should be disqualified on the grounds that the creditor casting the votes is controlled by the sovereign or has otherwise been influenced by the sovereign. Moreover, and as is described in Section VII, if the amendment provides for the creation of creditor classes, disputes may arise as to whether such classes are discriminatory. Finally, and as is described in Section VII, the SDDRF would be expected to resolve disputes relating to the formation and operation of creditors/ committees, including disputes that may arise as to whether it is adequately representative or whether the fees to be borne by the debtor are excessive.

262. As a dispute resolution forum that is dedicated to the SDRM process, the SDDRF would likely provide the advantage of being able to resolve the above disputes in a rapid manner.

\section{Injunctive Relief}

263. As discussed in Section VI, one possible design feature would be to empower the SDDRF to issue an order that would require a court outside the territory of the sovereign to issue a stay on specific enforcement action brought by a creditor. This power would be circumscribed: the injunction could only be issued at the request of the debtor and upon approval of creditors. An important question to be resolved is how creditor approval would be obtained.

\footnotetext{
${ }^{43}$ The administrative process of sending notices, processing filings, record-keeping, vote-tallying, etc., could be quite considerable, depending on the number of claims and creditors. The SDDRF would need a registry capable of performing such functions. The registry would be part of the secretariat discussed above.
} 


\section{Application of Governing Law}

264. On substantive issues (example, such as an interpretation of the validity of a claim), the SDDRF would apply the relevant national law (either lex contractus for interpretation, or the sovereign debtor's law regarding a dispute on, for example, the authority of an official to borrow on behalf of the debtor). However, on procedural issues, such as claims of undue influence on certain creditors or abuse of the voting process, the SDDRF would apply its own law (lex fori). ${ }^{44}$

265. Decisions reached in one SDDRF case would not be formally binding in another case (i.e., no stare decisis). However, to enhance the SDRM's goals of predictability and order, the SDDRF could, from time-to-time, meet en banc to establish general principles of law developed from the cases before it, which successive panels would generally be expected to follow.

266. Finally, the Executive Board's power to interpret the Fund's Articles (pursuant to Article XXIX) would not apply to the SDDRF's interpretation of those provisions of the Articles that relate to the SDRM.

\section{Relationship with National Laws and Legal Effect and Finality of SDDRF Decisions}

267. A distinction should be made between three categories of decisions that the SDDRF would be required to make.

268. The first category of decisions would involve a certification that a restructuring agreement between the debtor and a qualified majority of its creditors has been reached in accordance with the required procedures. Accordingly, certification would be based exclusively on agreements made by the debtor and a qualified majority of creditors; it would not be based on the exercise of the SDDRF's discretion. The role of the SDDRF would be simply to certify that the agreement had been reached in accordance with procedural requirements. It should be noted that certain decisions in the dispute resolution process that

\footnotetext{
${ }^{44}$ With respect to the statute of limitations, which may be seen by some as a substantive matter and by others as a procedural matter, it would be useful to clarify that the lex contractus will apply, in order to avoid having to adopt special rules for the SDDRF. This approach seems consistent with the evolution of international rules on conflicts of laws and has been accepted also in countries that previously applied the lex fori in such cases. For instance, Article 10 of the Rome Convention on the Choice of Law for Contracts, provides that the law applicable to a contract "shall govern ... prescription and limitation of actions." Article 10 of the Rome Convention has been given effect in the United Kingdom by the Contracts (Applicable Law) Act of 1990.
} 
are integral to the agreements listed above would be subsumed in the certification, and thus, would be binding. On their own, such decisions would not be binding. ${ }^{45}$

269. The above certifications would have a direct binding effect in member countries of the Fund (whether or not the member in question was a party to the proceeding) and would not be subject to challenge in domestic courts or in any other regional or international court or forum. ${ }^{46}$ Accordingly, and by way of example, once a certification has been issued regarding the effectiveness of the restructuring agreement, a domestic court could not enforce a claim of a minority dissident creditor under the original agreement (principle of res judicata).

270. An authentication procedure for presenting certifications of the SDDRF to domestic courts/authorities would be required. ${ }^{47}$

271. The second category of decisions would be those relating to dispute resolution and would have a different legal effect. For purposes of a proceedings under the SDRM, such decisions could not be challenged in any other forum. However, in the event that the SDRM proceedings terminate without a final agreement, any decisions rendered by the SDRM in the context of a dispute (e.g., the validity or value of the claim) would not be binding on a national court when the creditor proceeds to enforce its claim. If a restructuring agreement is

${ }^{45}$ Example: Creditor asserts a claim of 100, but SDDRF finds claims is only 50. Later, restructuring plan discounts all claims by $50 \%$, so creditor's claim is now only 25 . Certification would encompass both the value of the claim as 25 and the previous ruling on the value of the creditor's original claim.

${ }^{46}$ Decisions of dispute resolution bodies in other international organizations are not subject to challenge in domestic courts or any other fora. Article 53(1) of the ICSID Convention, for example, provides: "The award . . . shall not be subject to any appeal or to any other remedy except those provided for in this Convention." Article 23(1) and (2)(a) of the WTO Understanding establishes that WTO members shall not resolve disputes under the WTO agreements other than "through recourse to dispute settlement in accordance with the rules and procedures of this Understanding." Article 60 of the ICJ Statute states: "The judgment is final and without appeal."

Additionally, Article 54(1) of the ICSID Convention is explicit in establishing arbitral awards under the auspices of ICSID as equivalent to the decisions of a domestic court and, thus, directly binding, with no need for any further procedure to make the decision binding: "Each Contracting State shall recognize an award rendered pursuant to this Convention as binding and enforce the pecuniary obligations imposed by that award within its territories as if it were a final judgment of a court in that State."

${ }^{47}$ Article 54 (2) of the ICSID Convention provides: "A party seeking recognition or enforcement in the territories of a Contracting State shall furnish to a competent court or other authority which such State shall have designated for this purpose a copy of the award certified by the Secretary-General. Each Contracting State shall notify the Secretary-General of the designation of the competent court or other authority for this purpose and of any subsequent change in such designation." 
reached, however, a previous decision of the SDDRF regarding the validity or value of a creditors claim could not be challenged and, for this reason, the treatment of the creditor's claim under the restructuring agreement would be final.

272. The third category comprises orders issued by the SDDRF that stay creditor enforcement, to the extent that the SDRM contains such a feature. Such orders would be binding on courts outside the territory of the sovereign but would lose their legal effect either upon the expiration period provided in the order or the termination of the SDRM process, whichever is earlier. As noted in Section VI, in circumstances where such an order is issued, neither the debtor nor the individual creditors who approved the request for an order could be made liable in an action brought by the enforcing creditor regarding the damages caused by such an order.

\section{E. Accountability and Transparency of the SDDRF}

273. The SDDRF could be made accountable and transparent (not to the Fund, but to the world at large) by requiring that it publish an annual report. Its certifications and decisions would be public documents. ${ }^{4}$

\section{The Amendment AND ITS Consistency WiTh Domestic Legal SySTEMS}

274. As discussed in earlier papers, the SDRM would be established through an amendment of the Articles of Agreement of the Fund. The first part of this section discusses the authority of the Fund's members to rely upon an amendment of the Articles to achieve this result and, in that context, briefly analyzes some of the procedural issues that are relevant to the amendment process. The second part addresses two specific questions that have been raised regarding the consistency of the proposed amendment with the domestic laws of members; namely: (i) its application to existing claims and (ii) the role of the SDDRF vis a vis domestic courts.

\footnotetext{
${ }^{48}$ Article 15 of the UN Charter requires the ICJ to submit annual and special reports to the General Assembly. The Registrar is required to notify all members of the UN and others entitled to appear before the court of cases filed (ICJ Statute, Article 40). Hearings "shall be in public" unless the Court decides otherwise, or the parties demand so (ICJ Statute, Article 46). Judgments shall be read in open court, stating reasons on which they are based and names of the judges partaking in decision (ICJ statute, Articles 56 and 58). Of course, deliberations of the court take place in, and remain, secret, unless the court agrees to waive secrecy (ICJ Rules of Court, Article 21(1)).
} 


\section{A. Amending the Fund's Articles}

\section{Authority}

275. Pursuant to Article XXVIII, an amendment of the Fund's Articles will enter into force for all its members when it is accepted by three-fifths of its members, having 85 percent of the total voting power. Since its entry into force in 1944, the Articles have been amended on three separate occasions. Some of these amendments involved major changes to the structure of the Fund, the scope of its mandate and the rights and obligations of its members. Nevertheless, they were considered compatible with an amendment procedure and did not involve the adoption of a new treaty.

276. Similarly the establishment of the SDRM could be achieved through an amendment as it is closely related to the role already assigned to the Fund under the Articles in the resolution of its members' external financial obligations. The main difference between this amendment and the preceding amendments is that it would affect the contractual rights of private parties rather than the relations among members. However, there is a clear precedent for such provisions in the Articles: Article VIII, Section 2(b) already limits the rights of private creditors to enforce certain contractual claims when they would conflict with certain legitimate interests of a member as recognized by the Articles. In many respects, the SDRM would be the analogue to Article VIII, Section 2(b): while the latter provision addressed contractual enforcement in the context of the imposition of exchange controls by a member, the former would address contractual enforcement in the context of a sovereign default. Both are designed to enhance the ability of the sovereign to resolve its external difficulties in a manner that is in the collective interest of the membership.

\section{For the above reasons, the staff is of the view that the SDRM may be established through an amendment of the Fund's Articles.}

\section{Procedure}

278. The procedure for the adoption of an amendment of the Fund's Articles is in three stages.

279. First, the Executive Board must decide to propose a draft text of the amendment for adoption by the Board of Governors. This decision is taken by a majority of the votes cast. The proposed text would be accompanied by an Executive Board report to the Board of Governors, which would become the official commentary for the amendment.

280. Second, the proposed amendment must be approved by the Board of Governors, also by a majority of the votes cast.

281. Third, it must be accepted by three-fifths of the members, having eighty five percent of the total voting power. 
282. With respect to the last stage, before a member communicates acceptance of an amendment, it must take all necessary steps required under its own domestic law to enable it to accept new treaty obligations. In that regard, it must also take all steps necessary to ensure that the amendment will be given full force and effect under domestic law. In some countries, once a new treaty obligation is accepted, it automatically becomes part of the domestic law. In other countries, however, it is necessary to actually incorporate the provisions of the treaty into domestic law for it to have legal effect domestically.

\section{B. Consistency with Domestic Legal Systems}

283. As noted above, when an amendment of the Fund's Articles enter into force, members have an obligation to ensure that all steps have been taken under their domestic law to ensure that the amendment will be given full force and effect in their territory. In some earlier discussions, Directors have asked questions as to whether the SDRM, as currently designed, would be consistent with their own legal system and, in particular, their constitutions. In that regard, two different concerns have been raised. First, would the domestic legal systems of member countries be able to accommodate the establishment of a new legal framework that would apply to existing claims? Second, would domestic legal systems allow for the adjudication of claims to be within the exclusive jurisdictions of an international body, such as the SDRM?

284. Clearly, the staff is not in a position to determine the answer to the above questions for all domestic legal systems. It is the prerogative and responsibility of each member to determine whether these-or any other-features of the SDRM would require changes in their own legal system. Nevertheless, based on the staff's own general understanding of these issues, the following observations can be made.

285. With respect to the application of the SDRM to existing claims, the staff's understanding is that amendments to domestic laws relating to claims enforcement, including the restructuring of these claims, are generally applied to claims that were outstanding at the time of the amendments. For example, much of the Fund's own conditionality during the Asian crisis - which sought to strengthen the insolvency and credit enforcement laws in these countries - was based on the general recognition that these changes would address problems relating to existing indebtedness.

286. Regarding the role of the SDDRF vis a vis domestic courts, the "due process" provisions of the constitutions of many countries require that a citizen have access to an independent adjudicative body in circumstances where its property rights are being affected. As a general matter, however, these provisions do not require that the adjudicative body be a domestic one. Parties to international contracts often agree that any disputes shall be subject to the exclusive jurisdiction of foreign courts. As discussed in an earlier section, only these claims would be subject to the SDRM and, therefore, the jurisdiction of the SDDRF. As a general matter, claims may also be adjudicated by a foreign adjudicative body even in circumstances where the body in question was not selected by the parties under the original contract. For example, the U.S. Supreme Court upheld the 
executive agreements that ended the Iranian hostage crisis, including an executive order suspending claims against Iran that were pending in federal courts and transferring them to an international arbitral tribunal. The court relied, inter alia, on the longstanding practice of settling claims of American citizens through international agreements. ${ }^{49}$

287. In assessing the consistency of SDRM with domestic law more generally, it is important to bear in mind that the most important decisions that will affect the rights of creditors will be made by a qualified majority of these creditors, not by the SDDRF. In this respect, the SDRM is designed to establish a collective decision making process among stakeholders, not a framework that allows for the SDDRF - or any other administrative body - to modify their contractual rights.

\section{General Conclusion}

288. The objective of the SDRM, as stated in the initial section of this paper, is to create a predictable framework that creates incentives for a sovereign and its creditors to reach an early and collaborative agreement on a restructuring of unsustainable debt in a manner that both preserves asset values and facilitates a return to medium term viability. As noted at the outset, the SDRM is only one element of the strategy needed to resolve capital account crises. Depending upon the circumstances of individual cases, its use will likely need to be complemented by measures to resolve balance sheet problems confronting the financial and corporate sectors. For this reason, therefore, it is imperative that progress also be made in developing complementary tools that will assist in resolving these issues.

289. Would the recommended features of the mechanism, as discussed in this paper, achieve the above-stated objective?

290. To the extent that delays in initiating and concluding an agreement are attributable to problems of collective action, the majority restructuring provisions of the SDRM would represent a major improvement over the existing system. By enabling a qualified majority of eligible creditors to bind all eligible creditors to the terms of the restructuring agreement, the mechanism would remove considerable uncertainty from the restructuring process. From an inter-creditor equity perspective, creditors will be much more likely to reach an early agreement if they have the assurance that their willingness to agree to an adjustment in the debt burden and profile will not be abused by holdouts who will press for better terms after the agreement has been reached. Moreover, to the extent that this dynamic makes it easier for the debtor to obtain a critical mass of support for a restructuring agreement, it will create incentives for the sovereign with unsustainable debt to initiate the restructuring process at an earlier stage in the crisis, thereby reducing the costs of restructuring for all parties concerned. Finally, since the mechanism will aggregate claims across instruments for voting and

${ }^{49}$ See Dames \& Moore vs. Regan, 453 U.S. 654 (1981). 
distribution purposes, it will effectively resolve collective action problems when they are most acute; i.e., when there are a multitude of outstanding debt instruments dispersed across different creditor groups.

291. But the benefits of the sovereign debt restructuring mechanism will not be limited to the resolution of collective action problems. As discussed in the initial section, the existing system is also hampered by other weaknesses. Inter-creditor equity problems are exacerbated by concerns regarding the absence of adequate information regarding the debtor's relative treatment of creditors. More generally, creditors are of the view that there is no predictable, fair and collaborative process that provides guidance as to how restructuring proposals are to be developed. By establishing a relatively clear procedure following activation that includes, among other things, transparency requirements regarding the treatment of all indebtedness, the mechanism will go a long way in addressing these "process" issues. Moreover, by giving legal standing to a representative creditors committee, the mechanism will catalyze creditor organization and will facilitate an early and collaborative dialogue between the sovereign and its creditors.

292. As currently conceived, the mechanism could deliver the above benefits with minimum interference with contractual rights. While the majority restructuring provisions would modify contractual claims, it would enhance the legal leverage of the qualified majority over the minority, but it would not increase the debtor's legal leverage over creditors.

293. By establishing an independent and centralized dispute resolution process, the mechanism will ensure that the benefits associated with an aggregated voting process do not lead to abuse. Since the SDDRF will be exclusively dedicated to the resolution of disputes that arise under the process, the integrity that it will give to the restructuring process should not come at the price of speed and efficiency.

294. If the SDRM is successful in establishing a framework that provides speed and predictability to the restructuring process, it will also enhance the stability of the international financial system. Specifically, if creditors have greater certainty as to the "ground rules" that will apply in these cases, it should assist them in pricing and assessing risk. For this reason, the mechanism may actually lower the cost of borrowing for emerging market economies.

\section{ISSUES FOR DISCUSSION}

295. Directors may wish to express their views regarding the basic rationale for the SDRM and the general principles that would guide its design, which are set forth in Section I and II.

296. The highlighted text in each section of the paper attempts to summarize the staff's preliminary recommendation as to how a specific feature of the SDRM should be designed. Executive Directors may wish to indicate whether they agree with these recommendations and the analysis upon which these recommendations are based. 
297. In addition, the paper has identified areas where the staff has not yet formed a view as to how a feature of the SDRM should be designed. Directors are invited to provide guidance on these issues. In particular:

298. (a) Should the claims of official bilateral creditors be restructured outside the SDRM or, alternatively, within the SDRM as a separate class?

299. (b) Directors may wish to express their views as to whether it is necessary to provide an independent confirmation of the member's representation of unsustainability as a condition for activation and, if so, who should perform this function.

300. (c) For purposes of implementing the proposed procedures for the provision of information, registration, verification and voting, should end-investors always be required to register?

301. (d) The paper proposes that creditors have the opportunity to decide to terminate the mechanism after the completion of the verification procedure in circumstances where the view that the activation is unjustified. Do Directors have a view as to the voting threshold that should apply to this decision?

302. (d) Should the SDDRF have the power to issue an order that would enjoin specific enforcement actions in circumstances where such an order is requested by the debtor and approved by creditors? How would creditor approval be obtained?

303. (e) Directors are invited to indicate the extent to which the proposed design of the SDRM would require changes in the domestic laws of members in their constituencies. 


\section{Sovereign Debt Restructuring Mechanism-Timeline}

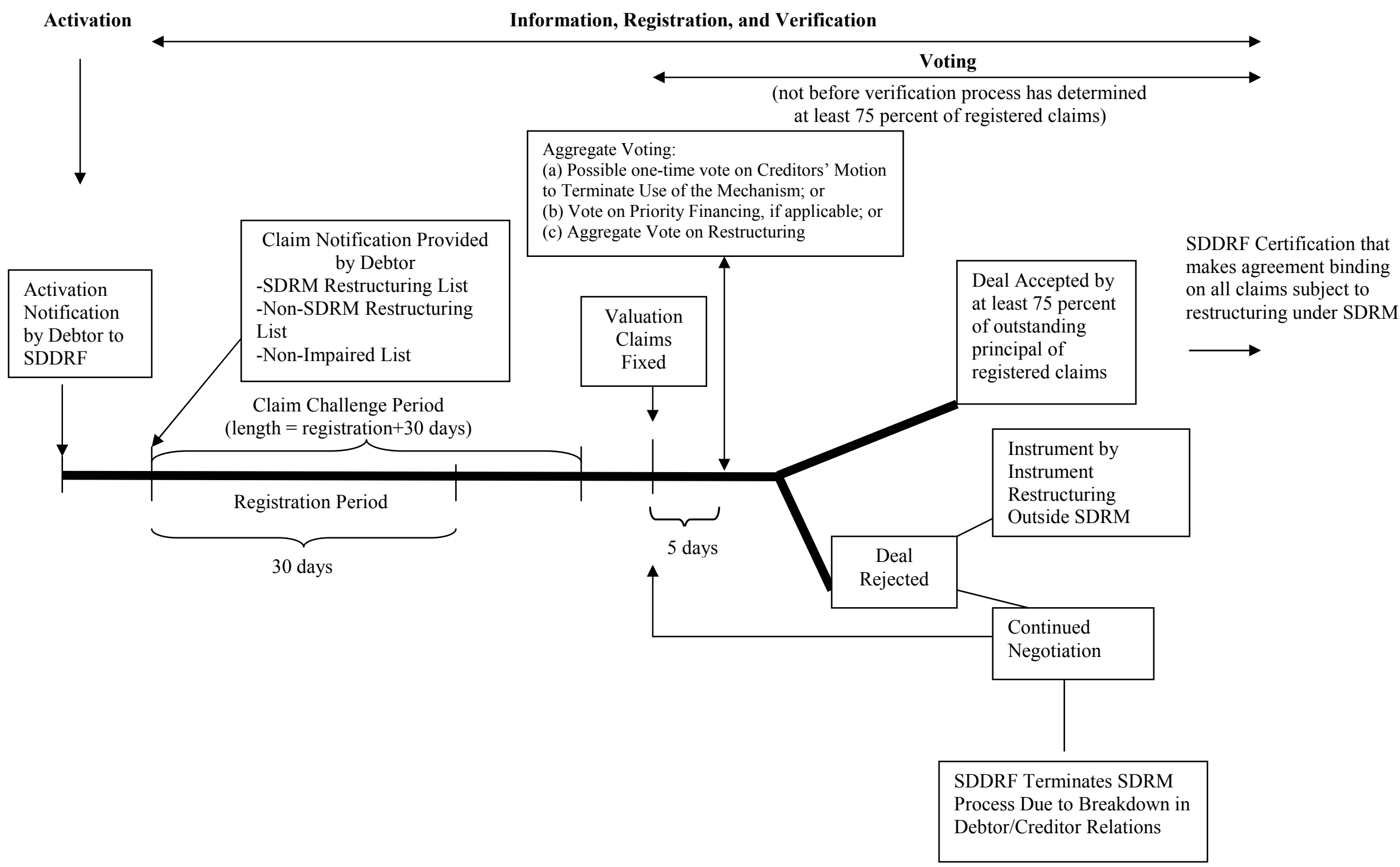

